\title{
Evaluation of A Proposed ASTM Standard Guide to Assess the Compatibility of Metal-Heat Transfer Liquid Pairs in Solar Heating and Cooling Systems
}

Paul Wencil Brown and John W. Grimes, II

Structures and Materials Division Center for Building Technology National Engineering Laboratory National Bureau of Standards Washington, D.C. 20234

October, 1979

Issued November 1979

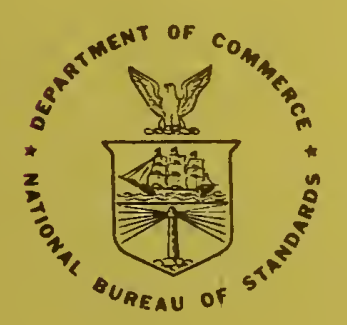

U.S. DEPARTMENT OF COMMERCE NATIONAL BUREAU OF STANDARDS 



\section{EVALUATION OF A PROPOSED ASTM}

STANDARD GUIDE TO ASSESS THE COMPATIBILITY OF METAL-HEAT TRANSFER

\section{LIQUID PAIRS IN SOLAR HEATING AND} COOLING SYSTEMS

Paul Wencil Brown and John W. Grimes, II

Structures and Materials Division

Center for Building Technology

National Engineering Laboratory

National Bureau of Standards

Washington, D.C. 20234

October, 1979

Issued November 1979

\section{U.S. DEPARTMENT OF COMMERCE}

Luther H. Hodges, Jr., Under Secretary

Jordan J. Baruch, Assistant Secretary for Science and Technology

NATIONAL BUREAU OF STANDARDS, Ernest Ambler, Director 

This study was undertaken as part of a round-robin evaluation of a proposed American Society for Testing and Materials (ASTM) testing methodology entitled, "Standard Guide for Laboratory Screening of Metallic Containment Materials for Use with Liquids in Solar Heating and Cooling Systems." This study was undertaken solely to evaluate the procedural aspects of each test method and the results of this study are not intended to provide an assessment of the suitability of any of the metals evaluated for use in solar heating and cooling systems. It was determined that the tests described in this Standard Practice can be carried out as a basis for evaluating metal-heat transfer liquid pair interactions under conditions simulative of various modes of solar containment system operation.

Key Words: Solar-Heat Transfer Liquid Containment; corrosion; elevated temperature; heat transfer; liquid flow rate; stagnation. 
LIST OF TABLES $\ldots \ldots \ldots \ldots \ldots \ldots \ldots \ldots \ldots \ldots \ldots \ldots \ldots \ldots \ldots \ldots \ldots \ldots \ldots \ldots \ldots \ldots$

LIST OF FIGURES $\ldots \ldots \ldots \ldots \ldots \ldots \ldots \ldots \ldots \ldots \ldots \ldots \ldots \ldots \ldots \ldots \ldots \ldots \ldots \ldots$

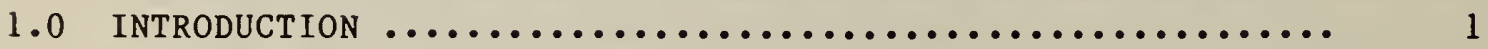

2.0 SELECTION OF MATERIALS AND SPECIMEN PREPARATION $\ldots \ldots \ldots \ldots \ldots$

3.0 TEST PROCEDURES AND RESULTS $\ldots \ldots \ldots \ldots \ldots \ldots \ldots \ldots \ldots \ldots \ldots \ldots \ldots$

3.1 Test A, Basic Immersion Test of Atmospheric

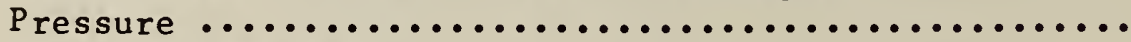

3.1 .1 Procedure $\ldots \ldots \ldots \ldots \ldots \ldots \ldots \ldots \ldots \ldots \ldots \ldots \ldots \ldots \ldots$

3.1 .2 Results $\ldots \ldots \ldots \ldots \ldots \ldots \ldots \ldots \ldots \ldots \ldots \ldots \ldots \ldots$

3.2 Test B, Heat Rejecting Surface Test of Atmospheric

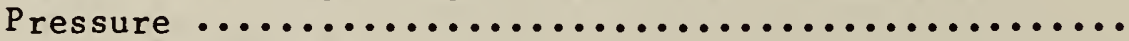

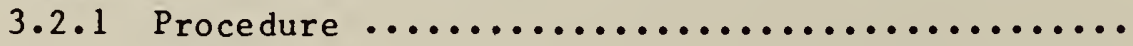

3.2 .2 Results $\ldots \ldots \ldots \ldots \ldots \ldots \ldots \ldots \ldots \ldots \ldots \ldots \ldots \ldots$

3.3 Test C, High Pressure Test ....................

3.4 Test D, Repeated Dip-Dry Test of Atmospheric

Pressure ...............................

3.4 .1 Procedure $\ldots \ldots \ldots \ldots \ldots \ldots \ldots \ldots \ldots \ldots \ldots \ldots \ldots \ldots$

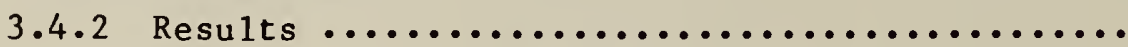

3.5 Test E, Imposed Crevice Test of Atmospheric

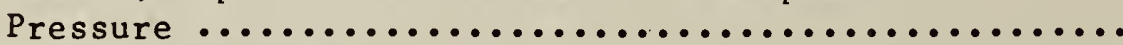

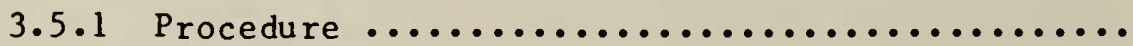

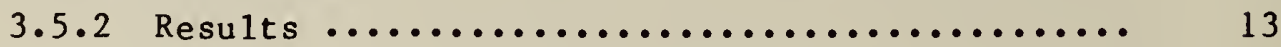

3.6 Test $F$, Tube Loop Test of Atmospheric Pressure ....... 14

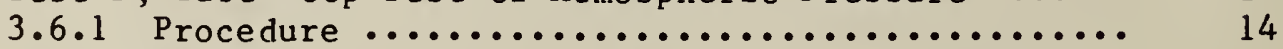

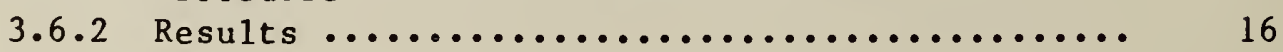

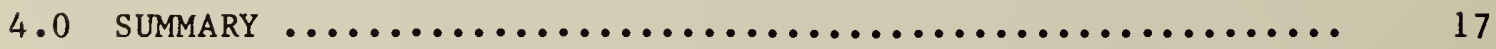

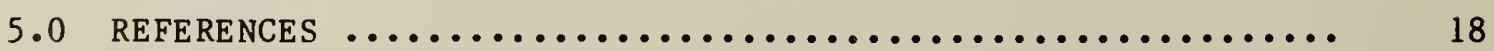

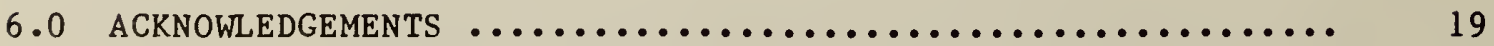


APPENDIX I - Draft Standard Guide for Laboratóry Screening of Metallic Containment Materials for Use with

Liquids in Solar Heating and Cooling Systems ...... 20

APPENDIX II - Specimen Cleaning Procedures ................ 37

APPENDIX III - Typical Blank Correction Factors for 1 inch by

2 inch ( $25 \mathrm{~mm}$ by $51 \mathrm{~mm}$ ) Specimens, Grams 
LIST OF TABLES

TABLE NO

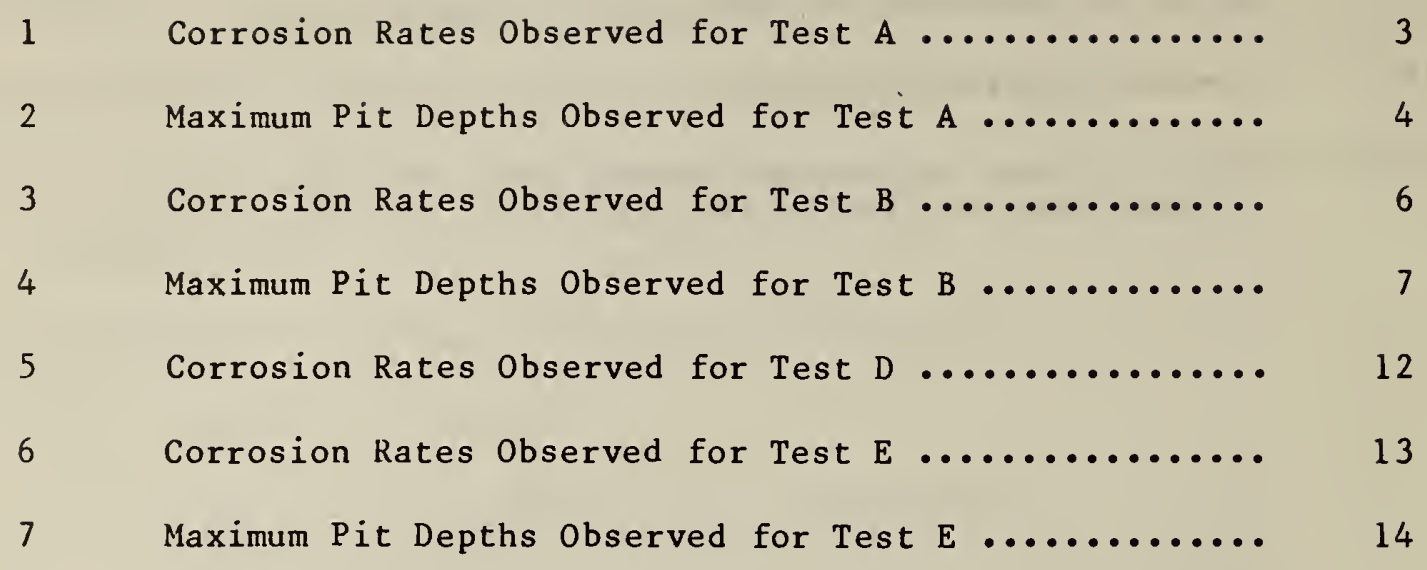

$\underline{\text { PAGE }}$

3

4

6

7

2

3

14

vi 
LIST OF FIGURES

Figure No.

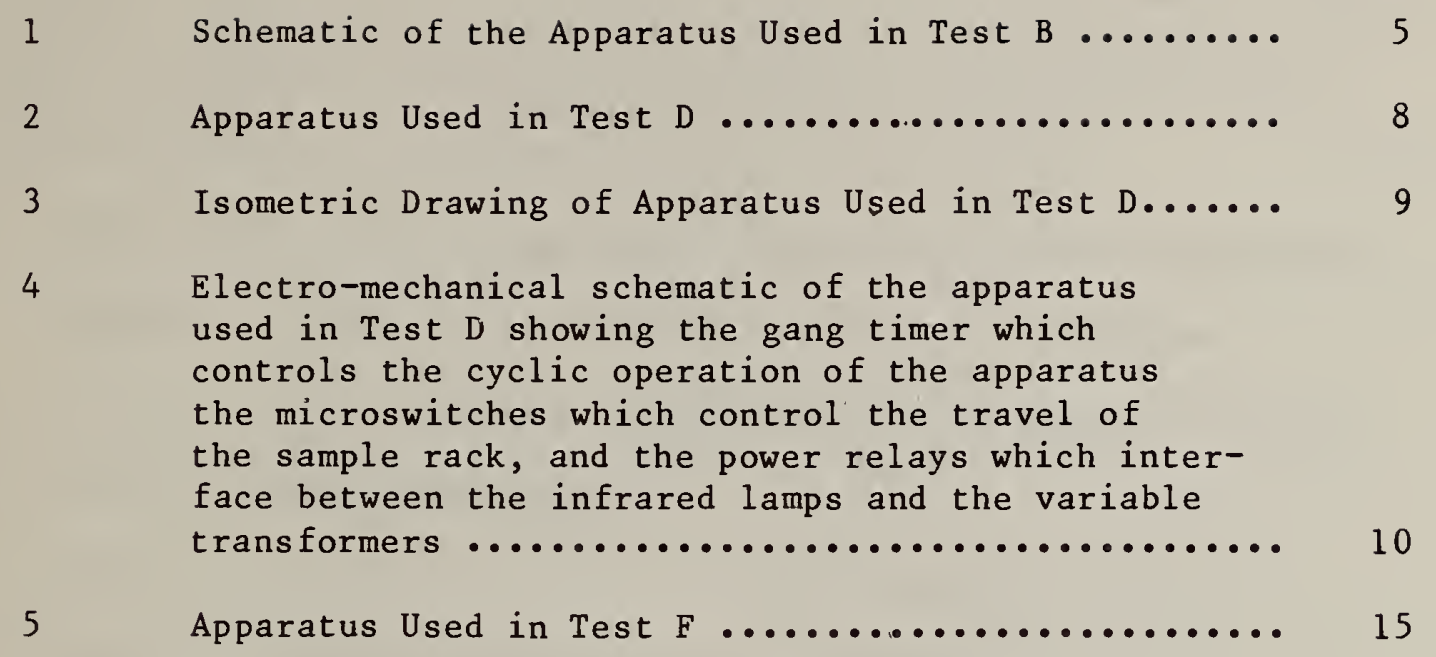

vii 



\subsection{INTRODUCTION}

This study was undertaken as part of a round-robin evaluation of a proposed American Society for Testing and Materials (ASTM) testing methodology entitled, "Standard Guide for Laboratory Screening of Metallic Containment Materials for use with Liquids in Solar Heating and Cooling Systems." This study was undertaken solely to evaluate the procedural aspects of each test method and the results of this study are not intended to provide an assessment of the suitability of any of the metals evaluated for use in solar heating and cooling systems.

The draft standard guide (Appendix I) includes six test methodologies:

$$
\begin{aligned}
& \text { Test A - Basic Immersion Test at Atmospheric Pressure } \\
& \text { Test B - Heat Rejecting Surface Test at Atmospheric Pressure } \\
& \text { Test C - High Pressure Test } \\
& \text { Test D - Repeated Drip-Dry Test at Atmospheric Pressure } \\
& \text { Test E - Imposed Crevice Test at Atmospheric Pressure } \\
& \text { Test F - Tube-Loop Test at Atmospheric Pressure }
\end{aligned}
$$

These test procedures were designed to allow the simulation of the following conditions to which a solar collector containment system may be subjected:

i) operating when filled with flowing heat transfer liquid (operating full, flow)

ii) filled with heat transfer liquid under no-flow conditions (stagnant, full)

iii) partially filled with heat transfer liquid under no-flow conditions (stagnant, partially full)

iv) empty

In addition, these test procedures were designed to allow assessment of the following factors which are likely to affect corrosion:

i) flow rate

ii) heat transfer mode

iii) alternating wetting and drying

iv) aeration or deaeration

v) the presence of crevices 
The rationale for selecting one or more of these tests to evaluate a specific aspect of metal-heat transfer liquid interaction is presented in the commentary for each test in Appendix I.

\subsection{SELECTION OF MATERIALS AND SPECIMEN PREPARATION}

Alloys of the principal metallic materials most likely to be used as liquid containment materials in solar heating and cooling systems were selected for use in evaluating these tests. In addition, the selection of $\mathrm{Al}, \mathrm{Cu}, \mathrm{S} / \mathrm{S}$ and mild steel allowed comparison of the various types of corrosion failure, e.g. pitting, crevice corrosion, and general. corrosion, as functions of each test. Two stainless steel (S/S) alloys, AISI 439, and 444, two copper ( $\mathrm{Cu}$ ) alloys, $\mathrm{CDA} 122$ and 706, two aluminum (A1) alloys, ANSI 1100 and 3003 , were used in evaluating tests $A, B, D$ and E. In addition SAE $1015 \mathrm{mild}$ steel and AISI 409 stainless steel were used in test $A$ only. It was anticipated that the the higher corrosion rates of these alloys would provide measure of the intersample variability in this test. ANSI 3003 Al tubing was used in Test F.

Specimens were prepared by shearing rolled stock to approximate coupon size. For the test requiring 2 inch by 2 inch ( $51 \mathrm{~mm}$ by, $51 \mathrm{~mm}$ ) coupons, specimens were sheared to 2.25 inches by 2.25 inches $(57 \mathrm{~mm}$ by $57 \mathrm{~mm}$ ). Similarly, for the tests requiring 1 inch by 2 inch $(25 \mathrm{~mm}$ by $51 \mathrm{~mm}$ ) coupons, specimens were sheared to 1.25 inches by 2.25 inches ( $32 \mathrm{~mm}$ by $57 \mathrm{~mm}$ ). These were then wet ground to their final dimensions with no more than 0.005 inch being removed on each of the last 3 passes of the grinding wheel. The edges of the coupons were then lightly wet-polished on 600 grit silicon carbide paper to remove burrs. The flat, commercial surfaces of the coupons were not abraded in any way. After measuring and recording the dimensions of the coupons, they were rinsed in water to remove any residual abrasive material. They were then scrubbed with a soft bristled brush using soapy water, rinsed with tap water followed by rinsing 3 times in distilled water, immersing twice in anhydrous ethanol and blotting dry. It was noted by visual examination that the copper base alloys were slightly tarnished. These were subsequently cleaned by immersion in the cleaning solution specified in ASTM G1-72 [1] (see Appendix II) for 10 seconds followed by rinsing and drying as discussed above. This procedure was adequate to completely remove the tarnish.

After cleaning and drying, the metal coupons were weighed to the nearest 0.00001 gram and placed in a dessicator.

\subsection{TEST PROCEDURES AND RESULTS}

\subsection{TEST A, Basic Immersion Test at Atmospheric Pressure}

\subsubsection{Procedure}

Test A, is a prescreening test which allows evaluation of the interaction between metal-1iquid pairs at elevated temperature. This test was carried out in glass reaction vessels immersed in an oil bath. Triplicate 1 inch by 2 inch ( $25 \mathrm{~mm}$ by $51 \mathrm{~mm}$ ) coupons of each alloy were placed in glass cradles which, in turn, were placed in reaction vessels. The reaction vessels 
were then filled with a selected volume of heat transfer liquid and the reaction vessel covers and condensers attached. These were placed in the oil bath. The bath temperature was increased to $90^{\circ} \mathrm{C}$ where it was maintained for the duration of the 30 day test.

The heat transfer liquid selected for use in this and the other tests was ASTM D 1384 tap water [2]. This was prepared by dissolving 148mg of sodium sulfate, $165 \mathrm{mg}$, of sodium chloride and $138 \mathrm{mg}$ of sodium bicarbonate per liter in distilled water.

The liquid volume to metal surface area ratio used in this test was $5 \mathrm{ml} / \mathrm{cm}^{2}$. The changes in liquid volume due to evaporation during the test were negligible.

At the conclusion of the test, the samples were removed, cleaned in accordance with ASTM G1-72 [1] (Appendix II), and weighed. To compensate for the removal of uncorroded metal as a result of the cleaning process, the coupons were recleaned and reweighed with the weight difference between the first and second cleaning being used as the correction factor (Appendix III).

\subsubsection{Results}

Table I lists the corrosion rates in mdd $\left(\mathrm{mg} / \mathrm{dm}^{2} / \mathrm{day}\right)$ which resulted from 30 days of immersion in unstirred ASTM D1384 tap water [2] at $90^{\circ} \mathrm{C}$.

Table I

Corrosion Rates Observed for Test A

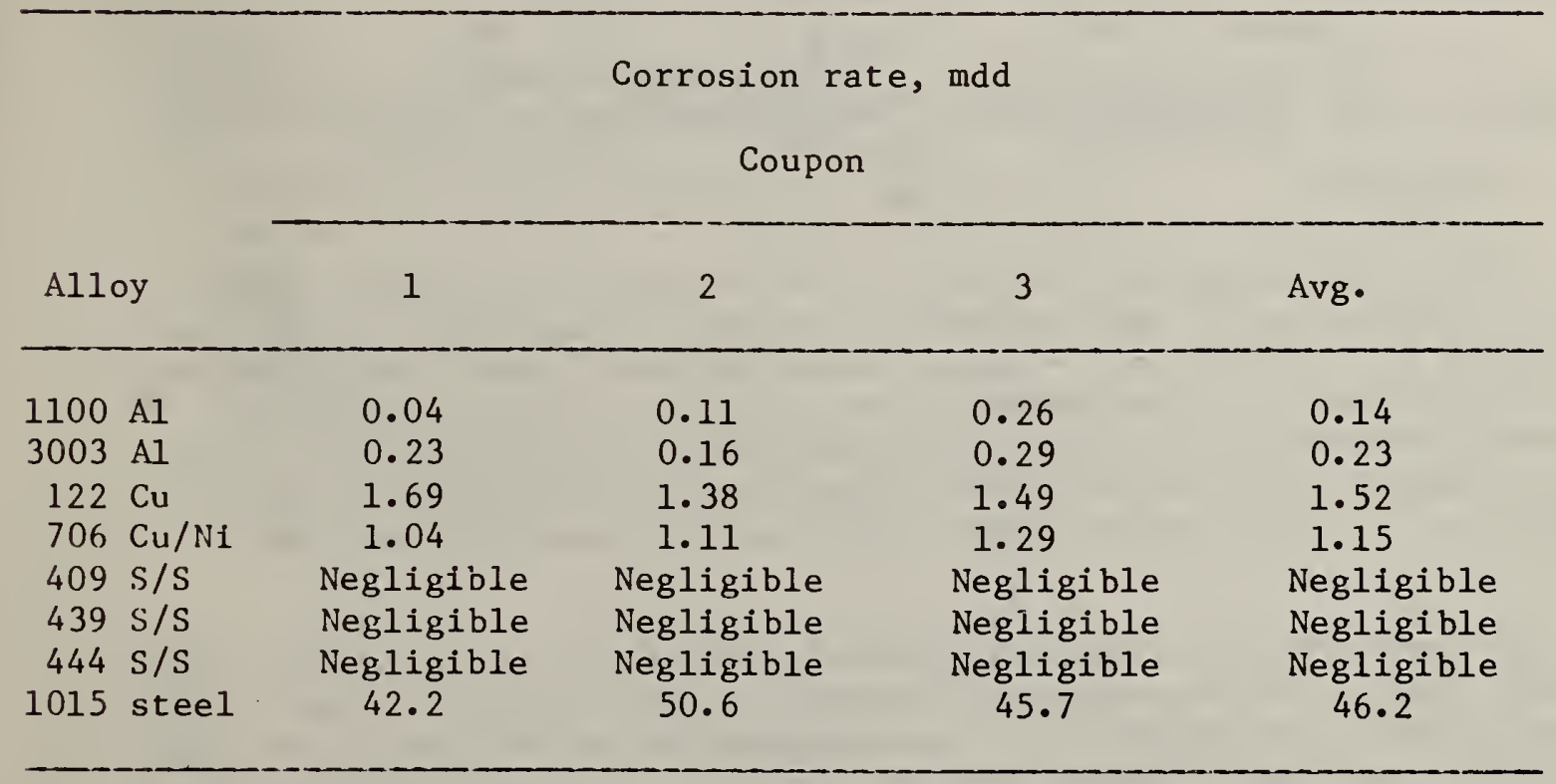

The depths of the pits which occurred as a result of carrying out Test A were measured by optical microscopy at 100X magnification. Maximum pit depths are listed in Table II. 
Table II

Maximum Pit Depths Observed for Test A

Maximum Pit Depths, mm

\begin{tabular}{|c|c|c|c|c|c|c|}
\hline \multirow[b]{3}{*}{ Alloy } & \multicolumn{4}{|c|}{$\begin{array}{c}\text { Coupon Number } \\
2\end{array}$} & \multicolumn{2}{|c|}{3} \\
\hline & \multicolumn{2}{|c|}{ Side } & \multicolumn{2}{|c|}{ Side } & \multicolumn{2}{|c|}{ Side } \\
\hline & 1 & 2 & 1 & 2 & 1 & 2 \\
\hline $1100 \mathrm{Al}$ & 0.15 & 0.11 & 0.05 & 0.04 & 0.08 & 0.18 \\
\hline $3003 \mathrm{Al}$ & 0.12 & 0.04 & 0.06 & 0.08 & 0.08 & 0.11 \\
\hline $122 \mathrm{Cu}$ & 0.03 & 0.05 & 0.03 & 0.07 & 0.09 & 0.02 \\
\hline $706 \mathrm{Cu} / \mathrm{Ni}$ & 0.03 & 0.02 & 0.04 & 0.01 & * & 0.02 \\
\hline $409 \mathrm{~s} / \mathrm{s}$ & * & * & * & * & * & * \\
\hline $439 \mathrm{~s} / \mathrm{s}$ & * & * & * & * & * & * \\
\hline $444 \mathrm{~S} / \mathrm{S}$ & * & * & * & * & * & $*$ \\
\hline 1015 Steel & Perfo & tion & Perf & ation & Perf & ation \\
\hline
\end{tabular}

*Pits present were too shallow to measure.

\subsection{TEST B, Heat, Rejecting Surface Test at Atmospheric Pressure}

\subsubsection{Procedure}

Test $B$ allows evaluation of the interaction between metal-liquid pairs under the conditions of heat transfer at elevated temperature. This test was carried out in modified 2-necked, round bottom flasks. Modification involved attachment to the bottom of each flask of a one inch $(25 \mathrm{~mm})$ i.d. neck terminating in a pipe flange, Figure 1. The 2 inch by 2 inch $(51 \mathrm{~mm}$ by $51 \mathrm{~mm}$ ) coupon was attached to the flask in a manner also shown in Figure 1. A viton* rubber gasket was used as a seal between the

* Certain trade names and company products are identified in order to adequately specify the experimental procedure. In no case does such identification imply recommendation or endorsement by the National Bureau of Standards, nor does it imply that the products are necessarily the best available for the purpose. 


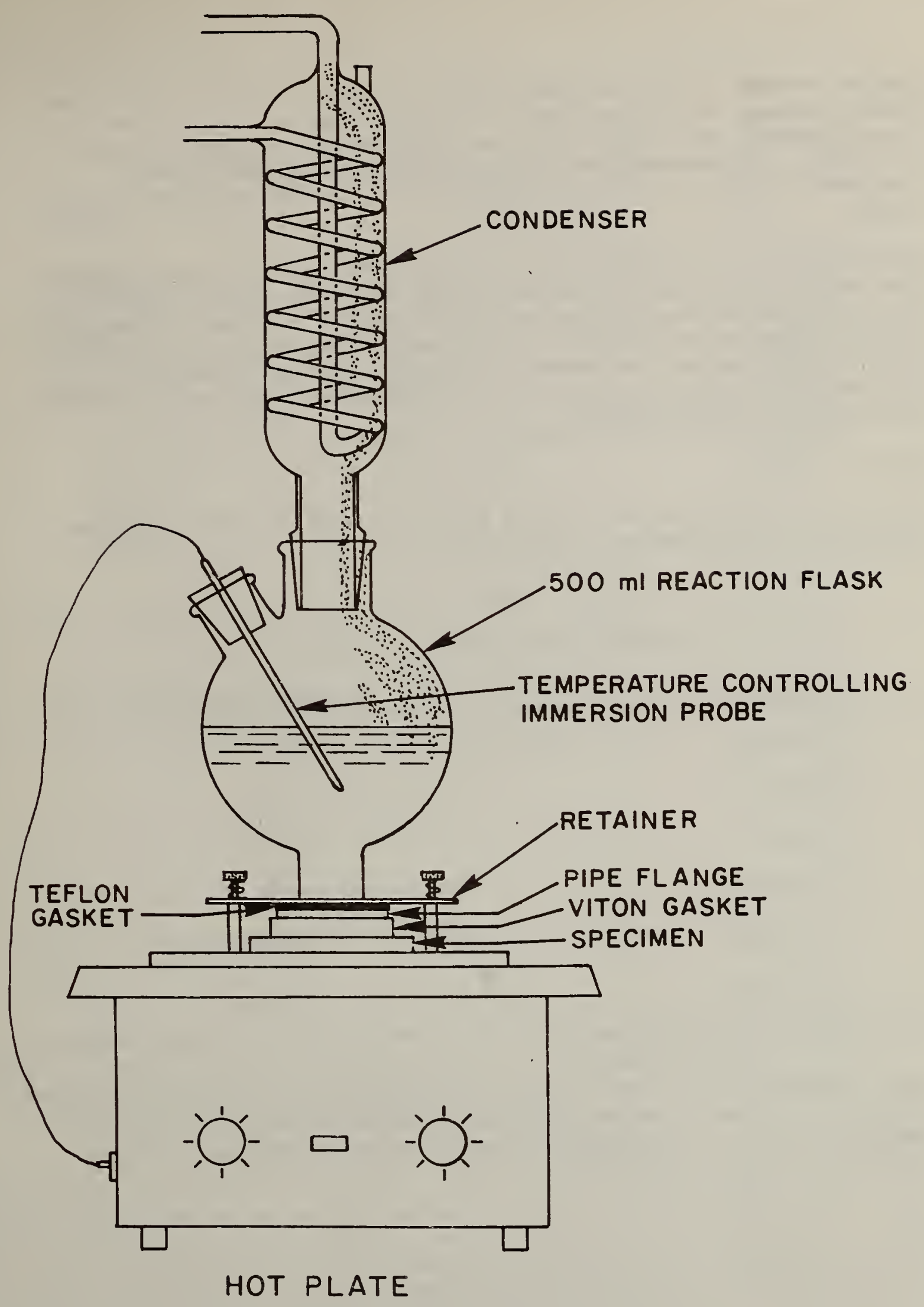

Figure 1. Schematic of the apparatus used in test B. 
bottom surface of the pipe flange and the coupon. A teflon gasket was placed between the top surface of the pipe flange and the retainer to avoid breaking the flange. Heat was supplied to the specimen using a hot plate. The temperature of the liquid was maintained at $100^{\circ} \mathrm{C}$

(nucleate boiling) by using an immersion probe which regulated the hot plate.

Each flask was filled with $350 \mathrm{ml}$ of ASTM D1384 water [2], the temperature was increased until nucleate boiling occurred, and this condition was maintained throughout the duration of this 30 day test. Changes in liquid volume due to evaporation were negligible. At the conclusion of the test the samples were removed, cleaned according to ASTM G1-72 [1], and weighed. A second cleaning and weighing was carried out to provide the blank correction factor.

\subsubsection{Results}

Table III lists corrosion rates in mdd which resulted when test $B$ was carried out for 30 days at $100^{\circ} \mathrm{C}$

Table III

Corrosion Rates Observed in Test B

Alloy

Corrosion rate, mdd

$1100 \mathrm{~A} 1$

1.42

$3003 \mathrm{Al}$

2.02

$122 \mathrm{Cu}$

8.32

$706 \mathrm{Cu} / \mathrm{Ni}$

4.03

$439 \mathrm{~s} / \mathrm{S}$

Negligible

$444 \mathrm{~s} / \mathrm{S}$

Negligible

Visual observations revealed evidence of both pitting and crevice corrosion in the $\mathrm{A} 1$ and $\mathrm{Cu}$ based alloys while the stainless steel alloys remained virtually uncorroded. Table IV lists the maximum pit depths observed. 
Table IV

Maximum Pit Depths Observed in Test B

Alloy

Pit Depth, mm

$\begin{array}{ll}1100 \mathrm{Al} & 0.04 \\ 3003 \mathrm{Al} & 0.04 \\ 122 \mathrm{Cu} & 0.05 \\ 706 \mathrm{Cu} / \mathrm{Ni} & \text { Pits present were too shallow to measure } \\ 439 \mathrm{~S} / \mathrm{S} & \text { No pits observed } \\ 444 \mathrm{~S} / \mathrm{S} & \text { No pits observed }\end{array}$

The pit distributions observed were not uniform. Maximum pit densities occurred within about 1-2 mm from the interfaces with the viton gaskets while the areas near the centers of the coupons were relatively free of pits. Shallow crevices ranging in width. from approximately $0.1 \mathrm{~mm}$ for the Al alloys to several $\mathrm{mm}$ for the $\mathrm{Cu}$ alloys were observed. These initiated at the edges of the viton gaskets and propaged outwards under the gaskets.

\subsection{TEST C, High Pressure Test}

Test $C$ was not part of the round-robin and was not evaluated in this study.

3.4 TEST D, Repeated Dip-Dry Test at Atmospheric Pressure

\subsubsection{Procedure}

Test D, allows evaluation of the effects of cyclic immersion of metallic specimens in heat transfer liquid coupled with intermediate drying. The The apparatus constructed to carry out this test is shown in Figure 2 and is represented schematically in Figures 3 and 4.

This apparatus consists of a frame, an electric motor and pulley arrangement to raise and lower the specimens, two banks of infrared lamps whose wattages are controlled by two $20 \mathrm{~A}$ variable transformers, a timer-cycler coupled with microswitches to control the dip-dry cycle, and a series of glass and teflon specimen holders attached to an arm which is raised and lowered on a predetermined cycle. Figure 4 shows the electrical-mechanical system used. The cyclic immersion and drying of the samples is controlled by a timer-cycler consisting of 4 microswitches, labelled $1,2,3$ and 4 , and four cams driven by a timer motor. Microswitches 1 and 2 control the 


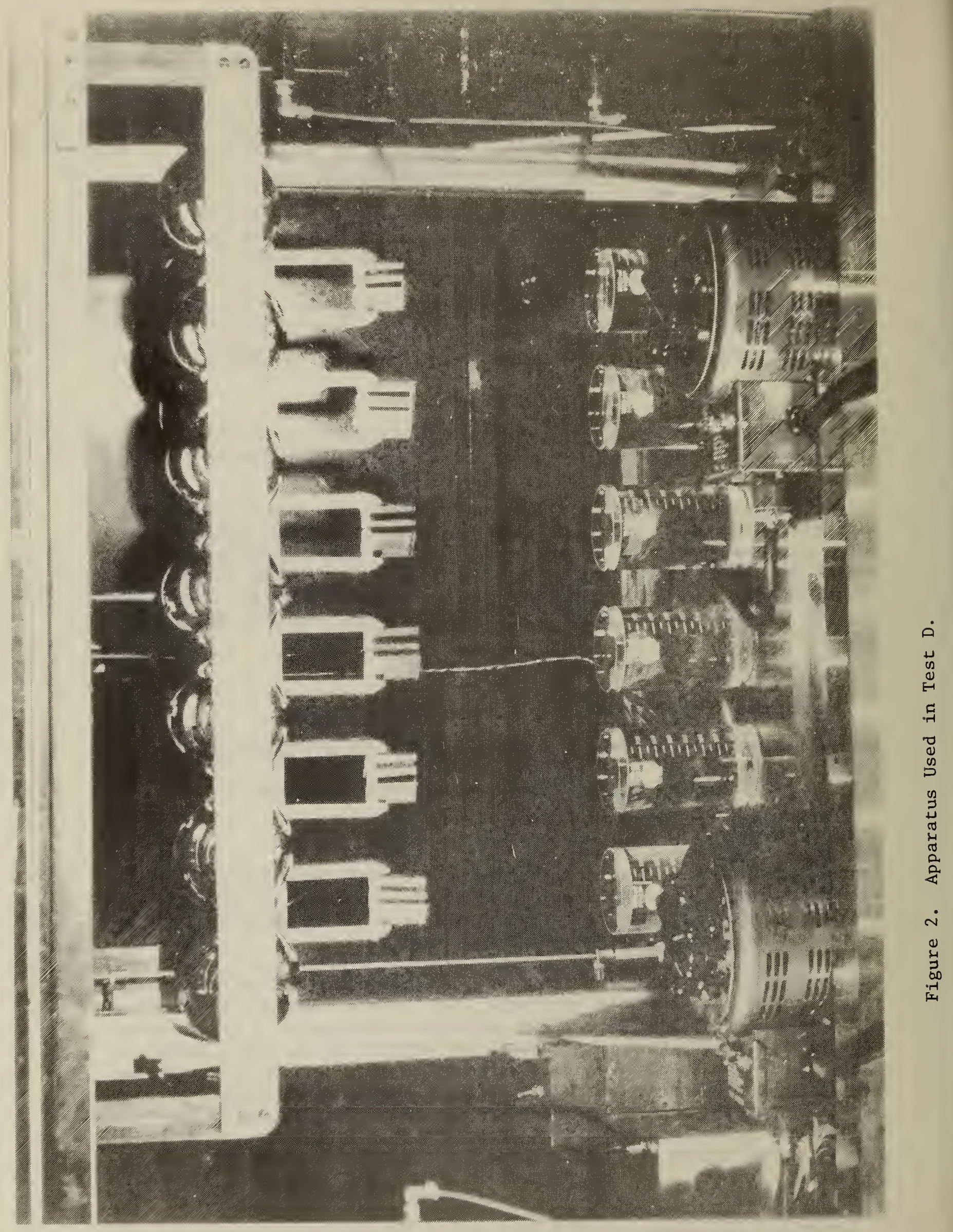




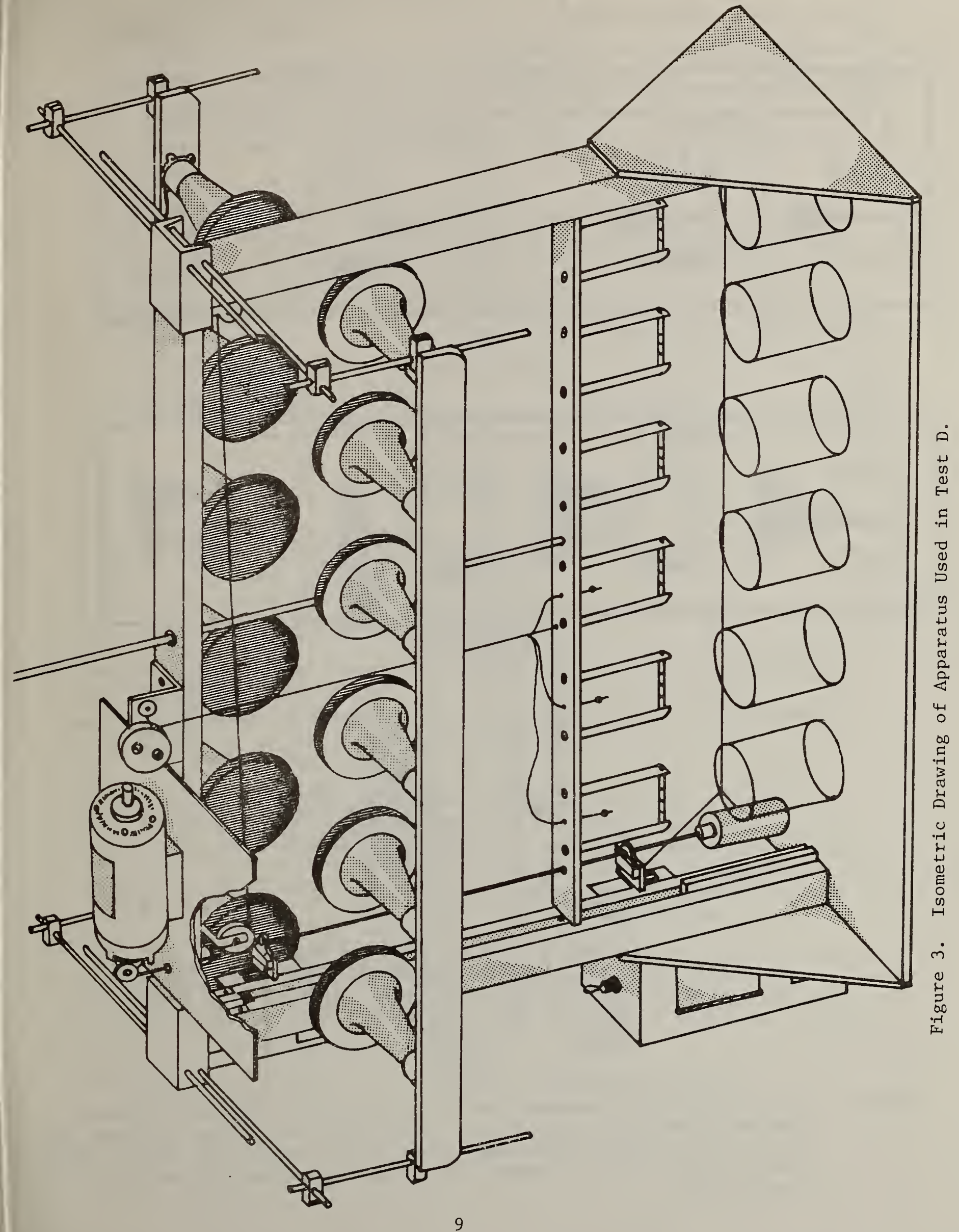




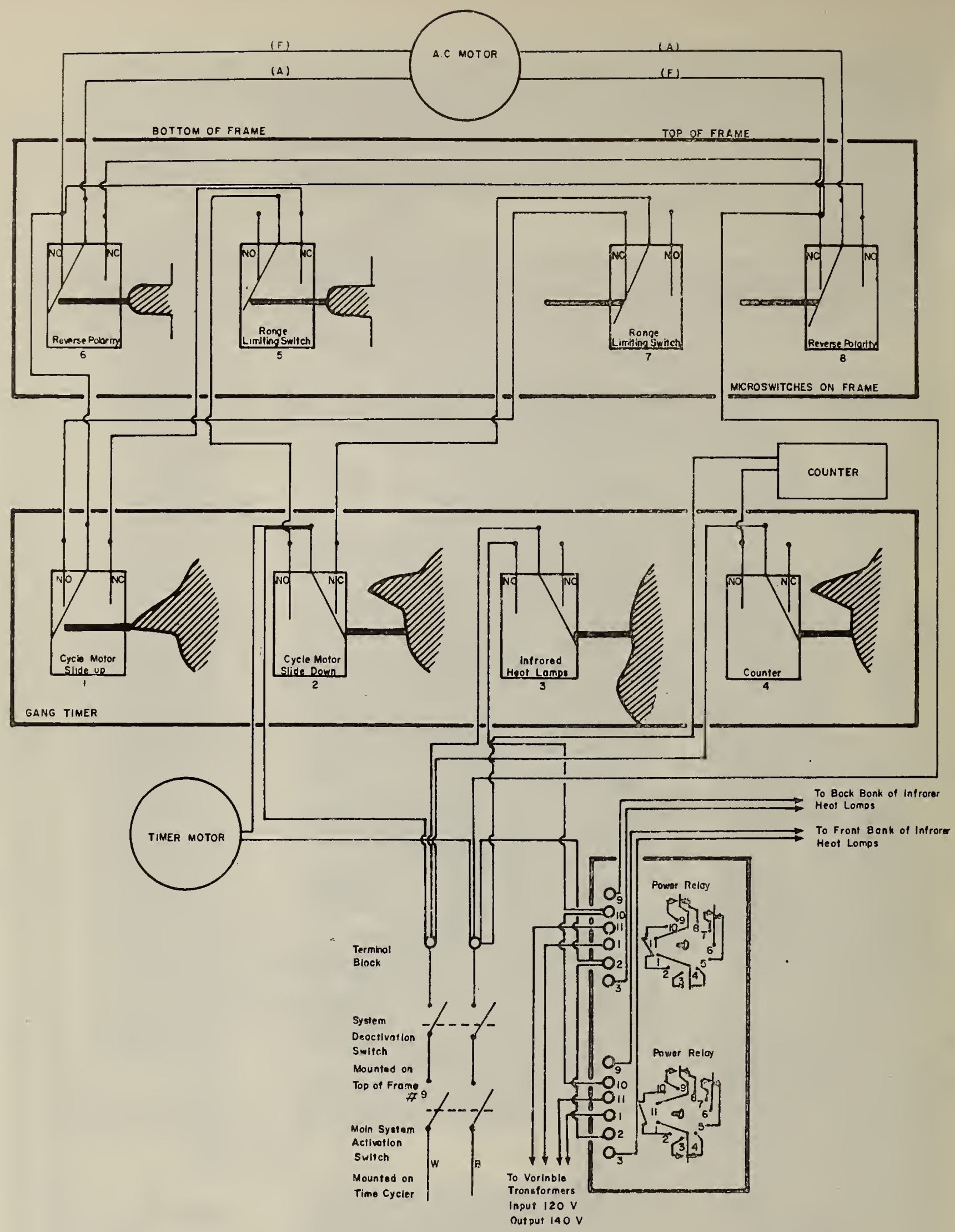

Figure 4. Electro-mechanical schematic of the apparatus used in Test D showing the gang timer which controls the cyclic operation of the apparatus the microswitches which control the travel of the sample rack, and the power relays which interface between the infrared lamps and the variable transformers 
vertical movement of the sample rack and operate in conjunction with the microswitches labelled 5, 6, 7 and 8 which are mounted on the frame of the apparatus. Microswitches 5 and 7 control the distance that the sample rack is allowed to travel while microswitches 6 and 8 reverse the polarity of the drive motor. A system deactivation microswitch, No. 9, is also located on the frame of the apparatus. Should the top range limiting microswitch, No. 7, fail to function, microswitch No. 9 will deactivate the system.

Microswitch No. 3 in the timer-cycler controls the duration over which the infrared lamps are activated. This is done by activating two power relays which interface between the two variable transformers and the front and rear banks of lamps. Microswitch No. 4 in the timer-cycler controls the counter. The drip dry cycle used consisted of the following sequence:

1) The specimens were initially immersed in the heat transfer liquid,

2) over a period of 15 seconds the specimens were raised 20 inches $(0.5 \mathrm{~m})$ to a position in the center of the 2 banks of infrared lamps,

3) the lamps were activated for $31 / 2$ minutes,

4) the lamps were switched off and the specimens were allowed to cool for a period of $51 / 2$ minutes,

5) the specimens were lowered into the heat transfer liquid over a period of 15 seconds,

6) the specimens rested in the heat transfer liquid for 30 seconds,

7) the cycle repeated.

The total cycle time was 10 minutes.

Triplicate specimens of the alloys tested were prepared by drilling a 21/64-inch $(8.3 \mathrm{~mm})$ hole approximately $1 / 4$ inch $(6.3 \mathrm{~mm})$ from the end of each coupon. These were then cleaned and weighed as described in test $A$, Section 2.0 above. The specimens were then secured to the apparatus using glass rods and teflon spacers. The specimens were oriented at an angle of $45^{\circ}$ to the banks of lamps to facilitate uniform heating.

The heat transfer liquid used was ASTM D1384 tap [2] and $1000 \mathrm{ml}$, high form beakers were used as containers. Each beaker was filled with $750 \mathrm{ml}$ of heat transfer liquid and evaporative losses were made up daily using distilled waţer. The liquid volume to metal surface ratio in this test was $10 \mathrm{~m} 1 / \mathrm{cm}^{2}$

This test was carried out for 30 days or 4320 dip-dry cycles. 


\subsubsection{Results}

Table $\mathrm{V}$ lists the corrosion rates in mdd which resulted from carrying out Test $\mathrm{D}$ for 30 days.

Table V

Corrosion Rates Observed for Test D

\begin{tabular}{|c|c|c|c|c|}
\hline \multirow[b]{2}{*}{ Alloy } & \multicolumn{3}{|c|}{$\begin{array}{c}\text { Corrosion rate, mdd } \\
\text { Coupon }\end{array}$} & \multirow[b]{2}{*}{ Avg } \\
\hline & 1 & 2 & 3 & \\
\hline $1100 \mathrm{Al}$ & 0.44 & 0.45 & 0.48 & 0.46 \\
\hline $3003 \mathrm{Al}$ & 0.20 & 0.27 & 0.47 & 0.31 \\
\hline $122 \mathrm{Cu}$ & 0.81 & 1.06 & 1.04 & 0.97 \\
\hline $706 \mathrm{Cu} / \mathrm{Ni}$ & 0.52 & 0.41 & 0.61 & 0.51 \\
\hline $439 \mathrm{~s} / \mathrm{S}$ & negligible & negligible & negligible & negligible \\
\hline $444 \mathrm{~S} / \mathrm{S}$ & negligible & negligible & negligible & negligible \\
\hline
\end{tabular}

\subsection{TEST E, Imposed Crevice Test at Atmospheric Pressure}

\subsubsection{Procedure}

Test $E$ allows evaluation of the interaction between metal-1iquid pairs at elevated temperature when an imposed crevice is present. This test was carried out in the same apparatus with Test A. Triplicate 1 inch by 2 inch (25mm by $51 \mathrm{~mm}$ ) coupons of the aluminum, copper, and 439 and 444 stainless steel alloys were tested. Specimens were initially prepared by attaching teflon blocks to the coupons with rubber bands in accordance with ASTM G48-76 [3]; however, the rapid deterioration of the rubber bands which occured, effectively eliminated the imposed crevice. As an alternative, a 0.250 inch $(6.4 \mathrm{~mm})$ hole was drilled through the center of each specimen and a threaded 1/4-20 teflon rod 1 inch $(25.4 \mathrm{~mm})$ in length inserted. Drilled and tapped teflon plugs $1 / 2$ inch $(12.7 \mathrm{~mm})$ in length and $5 / 8$ inch $(15.9 \mathrm{~mm})$ in diameter were threaded onto this rod and torqued to 3 inch-pounds $(0.34 \mathrm{Nm})$. This was adequate to form an imposed crevice.

Test $E$ was carried out for 30 days at $90^{\circ} \mathrm{C}$ in ASTM $\mathrm{D} 1384$ tap water [2]. The liquid volume to metal surface ratio was $5 \mathrm{ml} / \mathrm{cm}^{2}$. Changes in liquíci volume due to evaporation during the test were negligible. 


\subsubsection{Results}

Table VI lists the corrosion rate data in mdd which resulted from carrying out the imposed crevice test.

Table VI

Corrosion Rates Observed in Test $\mathrm{E}$

Corrosion Rate, mdd

Coupon

\begin{tabular}{lllll} 
Alloy & 1 & 2 & 3 & Avg \\
\hline $1100 \mathrm{Al}$ & 0.34 & 0.08 & 0.24 & 0.22 \\
$3003 \mathrm{Al}$ & 0.47 & 0.21 & 0.42 & 0.37 \\
$122 \mathrm{Cu}$ & 1.38 & 1.35 & 1.67 & 1.47 \\
$706 \mathrm{Cu} / \mathrm{Ni}$ & 1.22 & 1.09 & 1.28 & 1.20 \\
$439 \mathrm{~s} / \mathrm{S}$ & negligible & negligible & negligible & negligible \\
$444 \mathrm{~s} / \mathrm{s}$ & negligible & negligible & negligible & negligible \\
\hline
\end{tabular}


Table VII lists the maximum pit depths observed in the region of the imposed crevice.

Table VII

Maximum Pit Depths Observed in Test $\mathrm{E}$

Maximum Pit Depths, mm

Coupon Number

1

Side
2

3

Side Side

\begin{tabular}{lcccccc} 
A11oy & 1 & 2 & 1 & 2 & 1 & 2 \\
\hline $1100 \mathrm{A1}$ & 0.04 & 0.04 & 0.05 & 0.05 & 0.29 & 0.03 \\
$3003 \mathrm{N1}$ & 0.04 & 0.07 & 0.31 & 0.67 & 0.03 & 0.03 \\
$122 \mathrm{Cu}$ & 0.06 & 0.06 & 0.05 & $*$ & 0.03 & $*$ \\
$706 \mathrm{Cu} / \mathrm{Ni}$ & $*$ & $*$ & 0.05 & 0.02 & $*$ & $*$ \\
$439 \mathrm{~S} / \mathrm{S}$ & $*$ & $*$ & $*$ & $*$ & $*$ & $*$ \\
$444 \mathrm{~S} / \mathrm{S}$ & $*$ & $*$ & $*$ & $*$ & $*$ & $*$
\end{tabular}

*Pits present were too shallow to measure.

Comparison of the maximum pit depths and pit densities observed in Test $E$ with those observed in Test $A$ revealed that, while some coupons showed significantly greater pit depths and pit densities, this behavior was not consistent. As a consequence Test $E$ has been modified by striating the teflon surfaces which contact the coupons and by increasing the torque used to 7 inch-pounds $(0.79 \mathrm{Nm})$

\subsection{TEST F, Tube Loop Test at Atmospheric Pressure}

\subsubsection{Procedure}

Test $F$ is a qualitative test to allow examination of the effects of elevated temperature, heat trarisfer, and flow on the interaction of metal-fluid pairs. This test was carried out using the apparatus shown in Figure 5. 


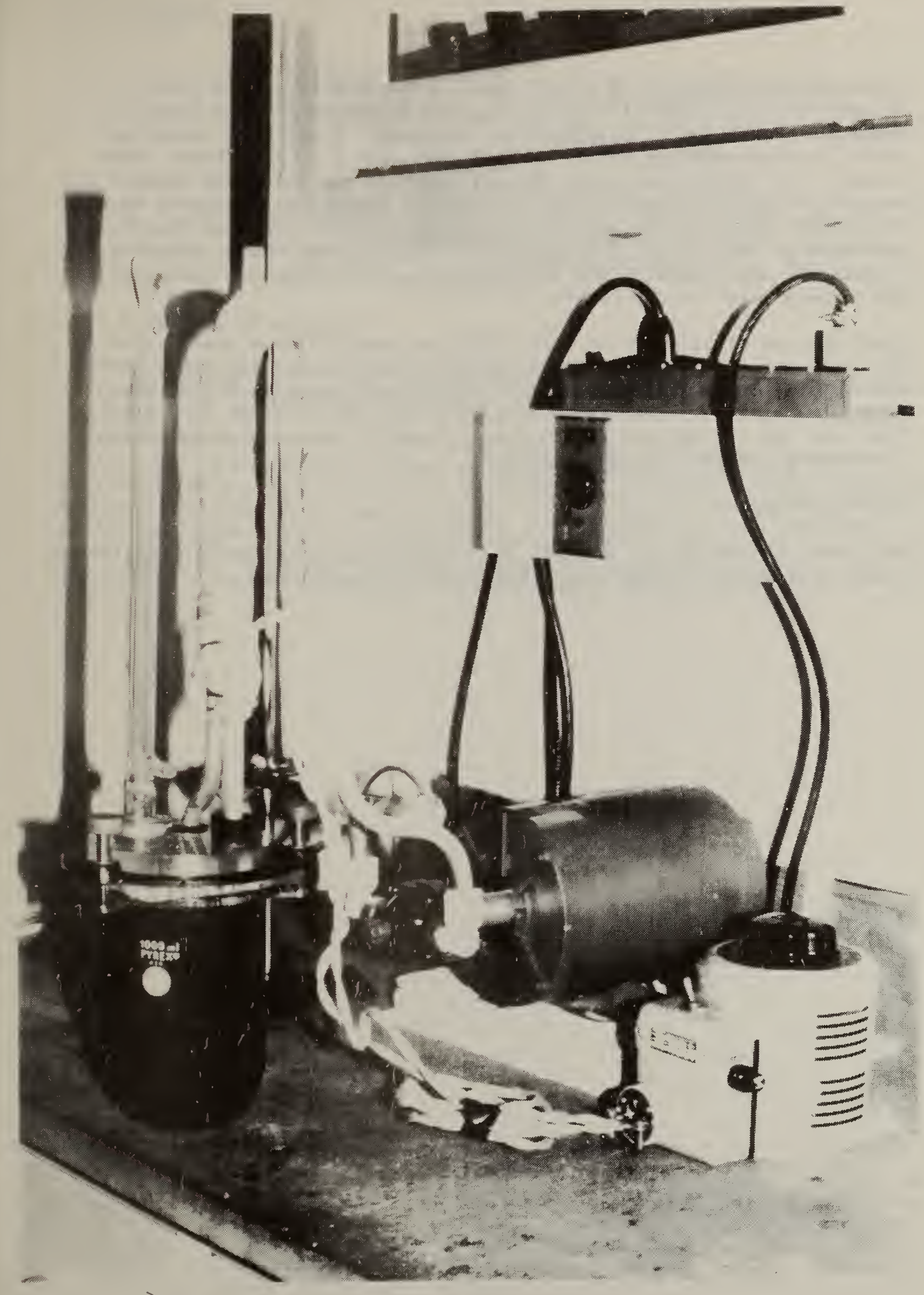

Figure 5. Apparatus used in test F. 
This apparatus consists of two, 3 foot $(0.9 \mathrm{~m})$ lengths of $3 / 8$ inch (9.5mm) i.d., $1 / 2$ inch $(12.7 \mathrm{~mm})$ o.d., 3003 Al tubing bent to form the configuration shown, a variable flow rate pump, a one-liter reaction vessel with a 4-opening cover, heating tape, and a $10 \mathrm{~A}$ variable transformer. Two lengths of tubing were attached to the inlet and outlet of the pump using polypropylene fittings and wrapped with heating tape. To minimize evaporation, rubber stoppers were fitted over the end of each tube to seal two of the openings in the reaction vessel cover. A condenser was placed in the third opening in the reaction vessel cover and a thermometer in the fourth.

Eight hundred millileters of ASTM D1384 tap water [2] was used as the heat transfer liquid. The liquid volume to metal surface ratio in this test was $6.1 \mathrm{ml} / \mathrm{cm} .{ }^{2}$ The temperature of the heat transfer liquid was maintained at $90^{\circ} \mathrm{C}$. The liquid flow rate used was $2 \mathrm{ft} / \mathrm{sec}(0.6 \mathrm{M} / \mathrm{sec})$. This test was carried out for 30 days. Loss of liquid due to evaporation during the test was neglegible.

\subsubsection{Results}

After the completion of the test, the tubes were longitudinally sectioned. Visual inspection revealed the presence of light pitting. 


\subsection{SUMMARY}

The methodology described in Test $A$ was found to be an adequate basis for a prescreening test. Test $A$ allowed separation of the corrosion rates of the aluminum and copper based alloys. In addition, the variability in the corrosion rates of the 1015 steel coupons was low.

The results of Test $B, D$, and $E$ also indicate that the variation in corrosion rate as a function of alloy composition may be observed. However, the variability in the pitting observed in the the aluminum samples in Test $E$ indicated an undersirable variability in crevice imposition. This test has been modified to reduce this variability.

Test $C$ was not carried out.

Test $F$, while qualitative in nature, did allow light pitting to be observed in the sample of 3003 aluminum tubing tested.

It was determined that the tests described in the Standard Guide maybe carried out in a reasonable time, at moderate expense, and, with the exception of Test $D$, with minimal equipment fabrication requirements. While the test methods were evaluated under a specific predetermined set of conditions in this study, they were found to contain sufficient flexibility to allow metal-1iquid pair evaluation under a variety of temperature, flow and aeration conditions simulative of various modes of solar containment system operation. 
5.0 REFERENCES

[1] ASTM G1-72, Preparing, Cleaning, and Evaluating Corrosion Test Specimens, Rec. Practice for 1978 Annual Book of ASTM standards Part 10.

[2] ASTM D1384-70, Corrosion Test for Engine Coolants in Glassware, 1978 Annual Book of ASTM Standards Part 30.

[3] ASTM G48-76, Pitting and Crevice Corrosion Resistance of Stainless Steels and Related Alloys by the Use of Ferric Chloride Solution, Test for, 1978 Annual Book of ASTM standards Part 10. 


\subsection{ACKNOWLEDGEMENTS}

The authors wish to thank members of materials task group of ASTM Committee 544 who originally developed the Recommended Practice evaluated in this report. In particular they wish to express their appreciation to Mr. James Hill for providing the stainless steel alloys, Dr. Edward Smith for providing the copper based alloys, and Dr. Coleman Grandstaff for providing the 3003 aluminum alloy samples. The authors also wish to acknowledge the Department of Energy, Office of Solar Applications for supporting this study. 


\title{
APPENDIX I
}

\author{
Draft Standard Guide for Laboratory Screening \\ of Metallic Containment Materials for Use with Liquids \\ in Solar Heating and Cooling Systems
}

\section{Scope}

1.1 This standard guide practice describes several laboratory test procedures for evaluating corrosion performance of metallic containment materials under conditions similar to those that may occur in solar heating and cooling systems. All test results relate to the performance of the metallic containment material only as a part of a metal/fluid pair. Performance in these laboratory test procedures, taken by itself, does not necessarily constitute an adequate basis for acceptance or rejection of a particular metal/fluid pair in solar heating and cooling systems, either in general or in a particular design. This standard guide is not intended to preclude the use of other screening tests, particularly when those tests are designed to more closely simulate field service conditions.

1.2 This standard guide describes apparatus and procedures for several tests, any one or more of which may be used to evaluate the deterioration of the metallic containment material in a metal/fluid pair. The procedures are designed to permit simulation, heating and cooling systems including (1) operating full flow, (2) stagnant full, (3) stagnant partial fill, and (4) stagnant empty. Particular attention should be directed to properly reflecting whether the system is open or closed to atmosphere.

1.3 This standard guide covers the following six tests:

1.3.1 Practice A - Basic Immersion Test at Atmopsheric Pressure

1.3.2 Practice B - Heat Rejecting Surface Test at Atmospheric Pressure

1.3.3 Practice C - High Pressure Test

1.3.4 Practice D - Repeated Dip Dry Test at Atmospheric Pressure

1.3.5 Practice E - Crevice Test at Atmospheric Pressure

1.3.6 Practice F - Tube Loop Test at Atmospheric Pressure

1.4 Practice A is concerned with the interaction of metal and fluid when both are at the same temperature with no heat transfer from one to the other. It is regarded as useful for plumbing, pumps, tanking, etc., but of less significance, taken by itself, for collector panels. Practices $B$ and $F$ are concerned with the deterioration of the metal when there is transfer of heat from the metal into the heat transfer fluid. These practices are especially applicable to the collector panel. Practice C permits a variety of tests but is especially useful in relation to systems that experience high temperatures, or are closed to the atmosphere. Practices $D$ and E evaluate specific corrosion problems that may be associated with particular metal/fluid pairs and particular designs of systems and components.

2. Applicable Documents

2.1 ASTM Standards: 
D 1384 Corrosion Test for Engine Coolants in Glassware

G 1 Preparing, Cleaning, and Evaluating Corrosion Test Specimens

G 48 Standard Test Method for Pitting and Crevice Corrosion

Resistance of Stainless Steels and Related Alloys by Use of Ferric Chloride Solutions.

\section{Significance and Use}

3.1 At this time none of these tests has been demonstrated to correlate with field service.

3.2 Because these procedures do not restrict the selection of either the containment material or the fluid for testing, it is essential that consideration be given to the appropriate pairing of metal and fluid. Likewise, knowledge of the corrosion protection mechanism and the probable mode of failure of a particular metal is helpful in the selection of test conditions and the observation, interpretation, and reporting of test results.

3.3 The design of solar heating and cooling systems strongly affects the applicability of the results of the laboratory screening tests. Therefore, the results of these laboratory procedures should be confirmed by component and systems testing under actual or simulated service conditions.

3.4 Table 1 is provided to assist in an orderly consideration of the important factors in testing. It is expected that the user of the test procedure will investigate a range of test times and temperatures for the containment material/fluid pair, and adjust the time and temperature of testing as necessary. (See Note 1)

3.5 It is essential for the meaningful application of these procedures that the length of test be adequate to detect changes in the nature of the fluid that might significantly alter the corrosivity of the fluid. For example,

Note 1 - Corrosion, whether general or localized, is a time dependent phenomenon. This time dependence can show substantial nonlinearity. For example, formation of a protective oxide will diminish corrosion with time, while certain forms of localized attack accelerate with time. The minimum time required for a test to provide a corrosion rate that can be extrapolated fo: the prediction of 1 ong-term performance varies widely, depending on the selection of metal and fluid, and on the form of corrosion attack. Therefore, it is not possible to establish a single minimum length of test applicable to all materials and conditions. However, it is recommended that for the tests described in this recommended practice, a test period of no less than 30 days be used. Furthermore, it is recommended that the effect of time of testing be evaluated to detect any significant time dependence of corrosion attack. 
exhaustion of chemical inhibitor or chemical breakdown of the fluid, may occur after periods of months in selected cycles of operation. (See Note 2)

\section{Materials and Reagants}

4.1 Any metallic material may be selected for evaluation. The material shall be capable of being described with sufficient accuracy to perit reproduction of the test.

4.2 Any heat transfer fluid may be selected for evaluation. However, it is expected that the fluid will be selected with consideration given to possible interactions of material and fluid under the conditions of testing. The fluid should be capable of being described chemically, as to its basic components and the presence or absence of minor components that affect the interaction with the metal. It is permitted to precondition the fluid before testing. Any such preconditioning treatment shall be described in the Report.

4.3 Particular attention shall be directed to avoidance of materials, fluids, or metal/fluid pairs that can be hazardous to the operator. The flammability, vapor pressure, and toxicity of the heat transfer fluid shall be known prior to initiation of testing and appropriate precautionary measures shall be taken to insure the safety of all test personnel.

\section{Sampling and Test Specimens}

5.1 The test specimens shall be selected from material that may reasonably represent that material as it would be applied in a solar heating and cooling system.

5.2 For laboratory corrosion tests that simulate exposure to service environments, a commercial surface, such as a mill finish, closely resembling the one that would be used in service, will yield the most significant results. For more searching tests of either the metal or the environment, standard surfaces finishes may be preferred. Ideally, the surface finish should be recorded in surface roughness terms, such as rms in.

\subsection{General Cleaning:}

5.3.1 General cleaning may be accomplished with a wide variety of cleaning media. Water-based cleaners should be followed by an alcohol

Note 2 - Many fluids that may be considered for solar applications contain additives to minimize the corrosivity of the fluid. Many such additives are useful only within a specific concentration range, and some additive may actually accelerate corrosion if the concentration falls bellow a critical level. Depletion kinetics can be a strong function of the exposed netal surface area. Therefore, for tests involving fluids with such additives, consideration must be given to the ratio of metal surface area to fluid volume as it may relate to an operating system. 
dip after thorough rinising. Solvent cleaners such as petroleum fractions, aromatic hydrocarbons, and chlorinated hydrocarbons are generally acceptable. Chlorinated solvents, however, should not be used on titanium, stainless steel, or aluminum. Mechnical cleaning of very smooth surfaces may be accomplished by the use of a paste of magnesium oxide or alumina.

5.3.2 Any of the methods suitable for cleaning a given corroded specimen may be used to compelte the cleaning of specimens prior to test, provided that they do not cause localized attack. The cleaned specimens should be measured and weighed. Dimensions determined to the third significant figure and weight determined in the fifth significant figure are usually satisfactory.

5.4 Metallurgical condition - Specimen preparation may change the metallurgical condition of the metal. For example, shearing a specimen to size will cold work and may possible fracture the edges. The specimen may be tested in this condition if it is believed that such condition may be encountered in service. In such case, the condition shall be described in the report of results. However, it is recommended that changes in metallurgical condition be corrected for customary testing. For example, sheared edges should be machined or the specimen annealed.

5.5 Alternative specimen designs, particulaly those incorporating crevices or metal coupling as may be encountered in application, are recommended.

5.6 For many metals, electrolytic cleaning is a satisfactory method for cleaning after testing.

5.6.1 The following method is typical: after scrubbing to remove loosely attached corrosion products, treat the specimen as a cathode in hot, dilute sulfuric acid under the following conditions.

5.6.1.1 Electrolyte - Sulfuric acid (5 weight percent),

5.6.1.2 Inhibitor - 0.2 volume percent organic inhibitor, (see Note 3)

5.6.1.3 Anode - Carbon or lead, (see Note 4)

5.6.1.4 Cathode - Test specimen,

5.6.1.5 Cathode Current Density - $2000 \mathrm{~A} / \mathrm{m}^{2}$

Note 3 - Instead of using 0.2 volume percent of any proprietary inhibitor, and $0.5 \mathrm{~kg} / \mathrm{m}^{3}$ of such inhibitors as diorthotolyl thiourea, quinoline ethiodide, or betanaphtol quinoline may be used.

Note 4 - If lead anodes are used, lead may deposit on the specimen and cause an error in the weight loss. If the specimen is resistant to nitric acid, the lead may be removed by a flash dip in $1+1$ nitric acid. Except for the possible source of error, lead is preferred as an anode as it gives more efficient corrosion product removal. 
5.6.1.6 Temperature $-75^{\circ} \mathrm{C}\left(165^{\circ} \mathrm{F}\right)$, and

5.6.1.7 Exposure Period - $3 \mathrm{~min}$.

5.6.2 After the electrolytic treatment, scrub the specimens with a brush, rinse thoroughly, and dry.

5.6.3 It should be noted that this electrolytic treatment may result in the redeposition of metal, such as copper, from reducible corrosion products, and thus, lower the apparent weight loss.

5.7 Chemical cleaning of specimens after testing is satisfactory provided the following methods are used.

5.7.1 Copper and Nickel Alloys - Dip for 1 to $3 \mathrm{~min}$. in $\mathrm{HCl}(1+1)$ or $\mathrm{H}_{2} \mathrm{SO}_{4}(1+10)$ at room temperature. Scrub 1 ightly with bristle brush under running water, using fine scouring powder if needed.

5.7.2 Aluminum Alloys - Dip for 5 to $10 \mathrm{~min}$ in a water solution containing 2 weight percent of chromic acid (chromium trioxide, $\mathrm{CrCO}_{3}$ ) and 5 volume percent of orthophosphoric acid $\left(\mathrm{H}_{3} \mathrm{PO}_{4}, 85\right.$ percent $)$ maintained at $80^{\circ} \mathrm{C}\left(175^{\circ} \mathrm{F}\right)$. U1trasonic agitation will facilitiate this procedure. Rinse in water to remove the acid, brush very 1 ightly with a soft bristle brush to remove any loose film, and rinse again. If film remains, immerse 1 min in concentrated nitric acid and repeat previous steps. Nitric acid alone may be used if there are no deposits.

5.7.3 Tin Alloys - Dip for $10 \mathrm{~min}$ in boiling trisodium phosphate solution (15 percent). Scrub lightly with bristle brush under running water, and dry.

5.7.4 Iron and Streel - Suitable methods are:

5.7.4.1 Preferably, use electrolytic cleaning (Section 5.6)

5.7.4.2 Immerse in Clark's solution (hydrochloric acid - 100 parts, antimonious oxide - 2 parts, stannows chloride - 5 parts) for up to $25 \mathrm{~min}$. Solution may be cold, but it should be vigorously stirred.

5.7.4.3 Remove scales formed on steel under oxidizing conditions in 15 volume percent concentrated phosphoric acid containing 0.15 volume percent of organic inhibitor at room temperature.

5.7 .4 .4 Clean stainless steel in 20 percent nitric acid at $60^{\circ} \mathrm{C}$ (140 F) For $20 \mathrm{~min}$. 
5.7.4.5 In place of chemical cleaning use a brass scraper or brass bristle brush or both, followed by scrubbing with a wet bristle brush and fine scouring powder. (See Note 5)

5.7.4.6 Other methods of cleaning iron and steel include immersion in hot sodium hydride, and cathodic pickling in molten caustic soda. (See Note 6)

\subsubsection{After cleaning and thorough rinsing, dry and weigh the samples.}

\section{Calculations and Interpretation of Results}

6.1 The deterioration of the containment material shall be determined by measurement of weight loss and by examination at $10 \mathrm{X}$ magnification for incidence of localized attack.

6.1.1 Whichever cleaning method is used, the possibility of removal of solid metal is present. Such removal would result in error in the determination of the corrosion rate. One or more cleaned and weighed specimens should be recleaned by the same method and reweighed. Loss due to this second weighing may be used as a correction of the first one. (See Note 7)

6.1.2 The total surface is calculated (making allowance for the change in surface area due to mounting holes). The weight loss is divided by the area to get a weight loss per unit area. This again may be divided by the duration of the test to get a corrosion rate in weight loss per unit area per unit time ( $\mathrm{such}$ as $\mathrm{mg} / \mathrm{dm}^{2} \cdot \mathrm{day}=\mathrm{mdd}$ ). This figure may be divided by the density of the metal and modified by appropriate conversion factors to obtain a figure in terms of rate of loss in thickness of the specimen (such as mils per year $=$ mpy).

\section{1 .2 .1 For instance:}

$$
\mathrm{R}_{\text {mdd }}=100,000 \frac{\mathrm{W}_{\mathrm{o}}-\mathrm{W}_{\mathrm{t}}}{\mathrm{AT}}
$$

where:

$$
\begin{aligned}
& \mathrm{R}_{\mathrm{mdd}}=\text { the corrosion rate, mdd, } \\
& \mathrm{W}_{\mathrm{O}}=\text { original weight, } \mathrm{g} \text {. }
\end{aligned}
$$

Note 5 - Such vigorous mechanical cleaning is applicable when wieght loss is large and hence errors in weight loss will produce only smalle errors in corrosion rates. Blank connections will be difficult to apply.

Note 6 - These methods may be hazardous to personnel. They should not be carried out by untrained personnel or without supervision.

Note 7 - The use of suitable inhibitors will diminish the attack and will permit reasonable degree of reproducibility with specimens varying in degree of rusting. 


$$
\begin{aligned}
& \mathrm{W}_{\mathrm{t}} \quad \text { final weight, } \mathrm{g} \text {, } \\
& \mathrm{A}=\text { area, } \mathrm{cm}^{2} \text {, and } \\
& \mathrm{T} \text { = duration, days. } \\
& 6.1 .2 .2 \mathrm{R}_{\mathrm{mpy}}=393.7 \frac{\mathrm{W}_{\mathrm{o}}-\mathrm{W}_{\mathrm{t}}}{\mathrm{ATD}} \\
& \text { where: } \\
& \begin{array}{l}
\mathrm{R}_{\text {mpy }}=\text { corrosion rate, mpy, } \\
\mathrm{W}_{\mathrm{O}}=\text { original weight, } \mathrm{g}, \\
\mathrm{W}_{\mathrm{t}}=\text { final weight, } \mathrm{g}, \\
\mathrm{A}=\text { area, } \mathrm{cm}^{2}, \\
\mathrm{~T}=\text { duration, years, and } \\
\mathrm{D}=\text { density, } \mathrm{g} / \mathrm{cm}^{3} .
\end{array}
\end{aligned}
$$

6.1.3 Any incidence of localized corrosion, whether pitting, crevice attack, integranular attack, cracking, or any other form of localized attack, shall be identified and rated under at least $10 \mathrm{X}$ magnification, and shall be reported. The location, distribution, and maximum depth of attack shall be reported for any localized attack.

6.2 Any changes of the heat transfer fluid, e.g., appearance or odor, should be reported with the results. Any changes in the appearance or condition of the test apparatus indicative of interaction with the metal specimen or fluid shall be described.

6.3 In the event of film formation and buildup, the nature of the film and its degree of buildup shall be reported.

6.4 For the evaluation of containment material couple, an effort should be made to utilize the same procedures as for a single material test. However, because of the variability permitted in the design of the specimen for the couple, it may be appropriate to report weight loss or penetration. For all tests of metal couple/fluid performance, special attention should be given to observation and reporting of localized corrosion and evidence of galvanic attack.

\section{Report}

7.1 The containment material shall be identified by standard specification wherc applicable, or by chemical analysis. In case of identification by standard specification, supplemental identification by typical analysis for such specification, or by chemical analysis of the specimen is desirable.

7.2 The dimensions and configuration of the specimen shall be reported. In the case of metal couple, the description shall include at least the following elements: (1) a description of the individual components of the couple; (2) a description of the method of attachment or association of the couple 
including any third material introduced as a binder or for other function and the procedures of connection, e.g., surface preparation, conditions of attachment, and cleaning; (3) any change of the containment materials resulting from the coupling procedure; and (4) a description of the relative areas of exposure of the components of the couple to the heat transfer medium.

7.3 The heat transfer fluid shall be identified by standard specification where applicable, by initial chemical analysis, or by proprietary designation.

Use of trademarks, or names of patented or proprietary products, without accompanying chemical description is discouraged but not prohibited. For aqueous transfer fluid, the analysis of the water used shall be reported.

7.4 The test used shall be identified. The test conditions used shall be specified, including specimen preparation, time and temperature schedule, degree of atmospheric exposure of the heat transfer fluid, stirring, and flow rate, where applicable. The method of temperature measurement and control, with comment on its accuracy and precision, shall be described. The nature of boiling of the fluid shall be described if boiling was observed during the test. Any deviation from the standard procedure shall be reported and so identified as a deviation.

7.5 The report shall provide both weight loss and average penetration rate when applicable. The time dependence of the corrosion rate shall be commented upon (see Note 1, Section 3.4) with a plot of corrosion rate as a function of time being provided when this time dependence is significant. All instances of localized deterioration of the test specimen shall be reported. In the event of pitting or other non-uniform attack, the frequency of attack and maximum penetration shall be reported.

7.6 A commentary on the results and their interpretation, particularly their applicability to various designs or solar heating and cooling systems, is optional but desirable.

Practice A - Basic Immersion Test at Atmospheric Pressure

\section{Scope}

8.1 This test procedure is intended to provide a simple, rapid exposure test for evaluation of metal and fluid interaction. The apparatus, as typically constructed, is open to the atmosphere. Therefore, the results of this test procedure may not be applicable to closed systems. 


\section{Apparatus}

9.1 The vessel is typically a $1000 \mathrm{ml}$ beaker or reaction flask or heat resistant glass (see Note 8 ). Provision is made for closing the top of the reaction vessel while providing openings for temperature measuring devices, reflux conderiser, and stirring device, as necessary. The specimen may be suspended in a cradle of non-metallic material or supported by a rack either constructed of a non-metallic macerial or insulated so as to prevent galvanic interaction of specimen and rack.

9.2 The vessel may be heated by mantle, hot plate, or bath. Selection of heating method can affect accuracy of temperature control. For certain fluids the more localized heating typical of a hot plate in comparison with the constant temperature bath, may produce changes in the heat transfer fluids.

9.3 The fluid may be stirred to simulate flow conditions. For those fluids ir which aeration or deaeration can be simulated by gas sparging, the use of such sparging devices is optional. For low boiling fluids the use of a coid trap is recommended.

10. Procedure

10.l The specimen shall be cleaned in accordance with Section 5 and then weighed to an accuracy of $0.1 \mathrm{mg}$ immediately prior to testing. The specimen shall be suspended in a cradle or attached to a specimen rack and placed in the test vessel. The vessel shall be filled with the heat transfer fluid to cover specimen. A volume of about $500 \mathrm{ml}$ is recommended. Condenser, temperature measuring device, stixring device, and heating device shall be mounted as neressary.

10.2. Typically the vessel is then heated to the desired test temperature and held at that temperature for the duration of the test. However, it is permitted to select any schedule of times and tempexatures (see Note 1, Section 3.4 ).

Note 8 - For coriain contiainment materials there exists the possibility that silicate from the giass of the apparatus contaminating an aqueous heat transfer fluid, would significantly affect the corrosion observed in this test. The effect of silicate from this source would be minimal in those cases in which silicates are a part of the corrosion inhibitor system, ox in wich silicates are ntherwise present in the heat transfe: flujd. However, for those cases in which the affect of silicake from glassware could have a significant effect ci the results, jit is recommended that sthex matexials be used for the efparatus, such that no significant extraneous effects will be jintrofuced in the results of the testo (See Reiezence 1.) 
11.1 This test procedure describes a general procedure for detecting interaction of metal and fluid. Because of its simplicity and because it is based on standard practices of corrosion testing, it is believed that this test procedure will prove reproducible and repeatable with good accuracy. However, at this time their is not adequate data on the metals and fluids of solar applications to permit a statement of precision and accuracy. The procedure is set forth in this standard guide for the purpose of standardizing testing in order to develop meaningful precision and accuracy data.

Practice B - Heat Rejecting Surface Test at Atmospheric Pressure

12. Scope

12.1 This test procedure is intended to simulate deterioration of the containment material resulting from heat transfer through the containment material into the heat transfer fluid. If curvature of the heat transfer surface is anticipated to be significant, Practice F should be considered. The

apparatus, as typically constructed, is open to atmosphere. Therefore, results of this test procedure may not be applicable to closed systems.

\section{Apparatus}

13.1 A schematic of the apparatus is shown in Figure 1. It is typically a $500 \mathrm{ml}$ round bottomed reaction flask with a 1 in. (25 min) inside diameter pipe flange opening for the attachment of the specimen (see Note 7, Section 9.1). Provision is made for closing the top of the reaction flask while providing openings for temperature measuring devices, reflux condenser, and stirring device, as necessary. The gasket shall be of a material appropriate to the temperature and chemical environment so that there is no significant interaction, other than the mechanically imposed crevice, with the containment material or the heat transfer fluid.

13.2 The temperature shall be controlled so as to produce the desired test temperature on the surface of the specimen in contact with the test fluid. The accuracy and precision of such control can be significantly affected by the method of temperature measurement. A simple method would be the imbedding of a thermocouple in the specimen when specimen thickness is adequate, or bonding of the thermocouple to the specimen by welding or other such attachment. In many cases such methods would provide sufficient accuracy. When greater accuracy of temperature measurement is required, it is possible to use systems of two or more thermocouples through the thickness of the specimen, and to thereby calculate a surface temperature. For those tests dealing in effects of metal/ fluid interaction in a very narrow temperature range, such more accurate methods of temperature control are strongly recommended. The method used shall be described, with comment on its accuracy and precision, in the report of the results. 


\section{Procedure}

14.1 The specimen shall be cleaned, and weighed to an accuracy of 0.1 mg immediately prior to resting. The specimen shall be mounted between the gasket and heater, and secured to the reaction flask. The flask shall be filled with $250 \mathrm{ml}$ of the test fluid. Condenser, temperature measuring device, and stirring device shall be mounted as necessary.

14.2 It is permitted to select any schedule of times and temperatures (see Note 1, Section 3.4). It is recommended that consideration be given to anticipated field operation in the selection of a schedule of heating, holding, and cooling cycles. It is recommended that stirring be used for simulation of operating full flow conditions.

\section{Precision and Accuracy}

15.1 This test procedure has been used by one laboratory for the screening of stainless steels and various aequeous heat transfer fluids for application in solar collectors. The results are reported to have satisfactory repeatability and reproducibility, but no supporting data are provided. Therefore, the precision and accuracy of this test procedure are unknown. The procedure is set forth in this standard guide for the purpose of standardizing testing in order to develop meaningful precision and accuracy data.

Practice C - High Pressure Test

\section{Scope}

16.1 This test procedure is intended to simulate the conditions of high temperature and pressure in a pressurized system under stagnant full, stagnant partial fill, and stagnant empty conditions. This test procedure can provide for test conditions simulating operation of systems closed to atmosphere.

\section{Apparatus}

17.1 This test is performed using an autoclave, or comparable device, capable of producing the required conditions of temperature and pressure. Specinens shall be independently supported from one another by a rack, and may be suspended in cradles or directly mounted on the rack. Supporting materials shall be selected so as to avoid interaction with the specimens or test fluid (see Note, 8 Section 9.1), and mounting shall be accomplished so as to avoid any galvanic interaction.

\section{Procedure}

18.1 The specimen shall be cleaned, and weighed to an accuracy of $1 \mathrm{mg}$ immediately prior to testing. The specimen shall he mounted in a cradle or on the rack. The rack shall be placed in the test chamber and the chamber shall be filled with the test fluid so that the specimen is totally immersed, partially immersed, or suspended in the vapor phase as desired. The chamber shall be sealed. 
18.2 The test may be run for any selected schedule of time, temperature, and pressure. (See Note 1, Section 3.4).

19. Precision and Accuracy

19.1 This test procedure has been used by one laboratory for the screering of copper and various heat transfer fluids for closed solar systems. The results are reported to have satisfactory repeatability and reproducibility, but no supporting data are provided. Therefore, the precision and accuracy of this test procedure are unknown. The procedure is set forth in this standard guide for the purpose of standardizing testing in order to develop meaningful precision and accuracy data.

Practice D - Repeated Dip Dry Test at Atmospheric Pressure

20. Scope

20.1 This test procedure is intended to simulate alternating wetting and drying conditions. This procedure, as customarily performed, is open to the atmosphere. Therefore, the results of this procedure may not be applicable to closed systems.

\section{Apparatus}

21.1 The apparatus shall consist of a hydraulically or mechanically operated arm from which the specimen is suspended in a glass cradle (see Note 8 , Section 9.1). The arm lowers the specimen into a beaker containing the test fluid and then raises the specimen into a device that will provide for drying of the specimen. Selection of the drying device shall take into consideration the possible degradation effects related to the method of drying, e.g•, degradation of fluid by infra-red radiation from heat lamps, or effects atmosphere exposure. A system of automatic control shall provide repeated cycles of selected periods of immersion and selected periods of drying.

\section{Procedure}

22.1 The specimen shall be cleaned, and then weighed to an accuracy of $0.1 \mathrm{mg}$ immediately prior to testing. The specimen shall be suspended from the movable arm in the cradle. A beaker of the test fluid be aligned under the specimen and the drying device and cycling device are activated.

22.2 Any cycle of dip and dry times may be selected. (See Note 1, Section 3.4).

\section{Precision and Accuracy}

23.1 This test procedure has been used by several laboratories in the past for evaluating the resistance of metals to corrosion resulting from drying of a corrosive environment splashed on the metal, particularly as ornamental automotive trim. The results are reported to have satisfactory repeatability and reproducibility, but no supporting data is provided. 
Therefore, the precision and accuracy of this test procedure are unknown. The procedure is set forth in this standard guide for the purpose of standardizing testing in order to develop meaningful precision and accuracy data.

Practice E - Crevice Test at Atmospheric Pressure

24. Scope

24.1 This test may be used to evaluate the genexal corrosion resistance and to detect susceptibility to crevice corrosion attack for metallic containment materials. This test procedure is generally similar to ASTM G48, a standard test method for stainless steels.

\section{Apparatus}

25.1 The apparatus for this test is described in ASTM G48. (See Note 8, Section 9.1).

25.2 Because the rubber band typically employed in the G48 test 1 oses elasticity at temperatures above $50 \mathrm{C}$, an alternative specimen design may be employed for higher temperatures. In this design washers of an inert material, e.g., acetal copolymer, are secured to the faces of the coupon. Grooves may be cut in the face of the washer that bears on the coupon so that each washer forms several separate crevice contacts. The ratio of the exposed area to the crevice area is significant, a ratio of 15 to 1 being typical. The plastic nut and bolt are torqued to 5 in-1b $(0.6 \mathrm{~N} \cdot \mathrm{m})$. (See 1 isted References.)

\section{Procedure}

26.1 The specimen shall be cleaned, and weighed to an accuracy of $0.1 \mathrm{mg}$ immediately prior to testing. The crevice is applied either by rubber band as described in 448 , or by application of washers as described in Section 25.2 . The specimen shall be placed in the test flask, fluid shall be added, and the condenser shall be installed. The flask shall. be heated to the desired test temperature (see Section 9.2).

\subsection{Any length of test time may be selected. (See Note 1 , Section 3.4 ).}

\section{Precision and Accuracy}

27.1 This test procedure is derived from ASTM G48 which describes the method for the evaluation of stainless steels using a solution of ferric chloride. It is expected, although data is not provided, that precision and accuracy comparable to that of $\mathrm{G} 43$ can be developed for stajinless steels tested with other aqueous media. No data are provided for stainless steels with non-aqueous media or other metals. The procedure is set forth in this standard guide for the purpose of standardizing in order to develop meaningful precision and accuracy data. 
Practice F - Tube Loop Test at Atmospheric Pressure

28. Scope

28.1 This test procedure is intended to simulate deterioration of containment materials when heat is transferred through the containment material tubing into heat transfer fluid inside the tube.

\section{Apparatus}

29.1 The apparatus for this test shall consist of a heating tape with appropriate power and control systems, and a variable flow pump with a reservior for the heat transfer fluid (see Note 8, Section 9.1). The apparatus shall be assembled as shown in Figure 2. Alternative methods of heating may be provided.

29.2 The primary sample typically consists of a $36 \mathrm{in.}$ ( $914 \mathrm{~mm}$ ) length of tubing bent around an $8 \mathrm{in.} \mathrm{(203} \mathrm{mm)} \mathrm{diameter} \mathrm{mandril} \mathrm{so} \mathrm{that} \mathrm{each} \mathrm{leg}$ of the U-bend is of approximately equal length. Other specimen designs are permitted if such more closely approximate conditions of application. Care should be taken in making the U-bend so that fluid flow through the tube is not significantly restricted. The tubing sample shall be mounted with an inclination of the plane of the U-bend at about 45 degrees to horizontal during testing. Secondary samples of similar or dissimilar metal tubing may be introduced in the loop as indicated in Figure 2.

30. Procedure

30.1 The U-bend specimen and any secondary specimens shall be cleaned and installed as shown in Figure 2. The U-bend shall be wrapped with a heating tape, or an alternative heating device shall be mounted. The reservoir shall be filled and the cycling mechanism for control of temperature and fluid flow is activated.

30.2 Any cycle of fluid flow and heating may be used for this test. (See Note 1, Section 3.4)

31. Precision and Accuracy

31.1 This test procedure has been used by one laboratory for the screening of aluminum and various heat transfer fluids. The results are reported to have satisfactory repeatability and repoducibility, but no supporting data are provided. Therefore, the precision and accuracy of this test procedure are unknown. The procedure is set forth in this standard guide for the purpose of standardizing heating in order to develop meaningful precision and accuracy data. 
References

1. For information on the effort of silicates from glass test apparatus, see Corrosion Inhibitors, C. C. Nathan, ed., NACE, 1973, p. 120-121.

2. For information on the design of Crevice Test Specimens, Particularly for Practice E, see D. B. Anderson, Galvanic and Pitting Corrosion Field and Laboratory Studies, R. Baboian, et. al•, eds., ASTM STP 576, 1976, 231-242; also R. J. Brighman and E. W. Tozer, Corrosion, 32 (7), $1976,274-276$. 


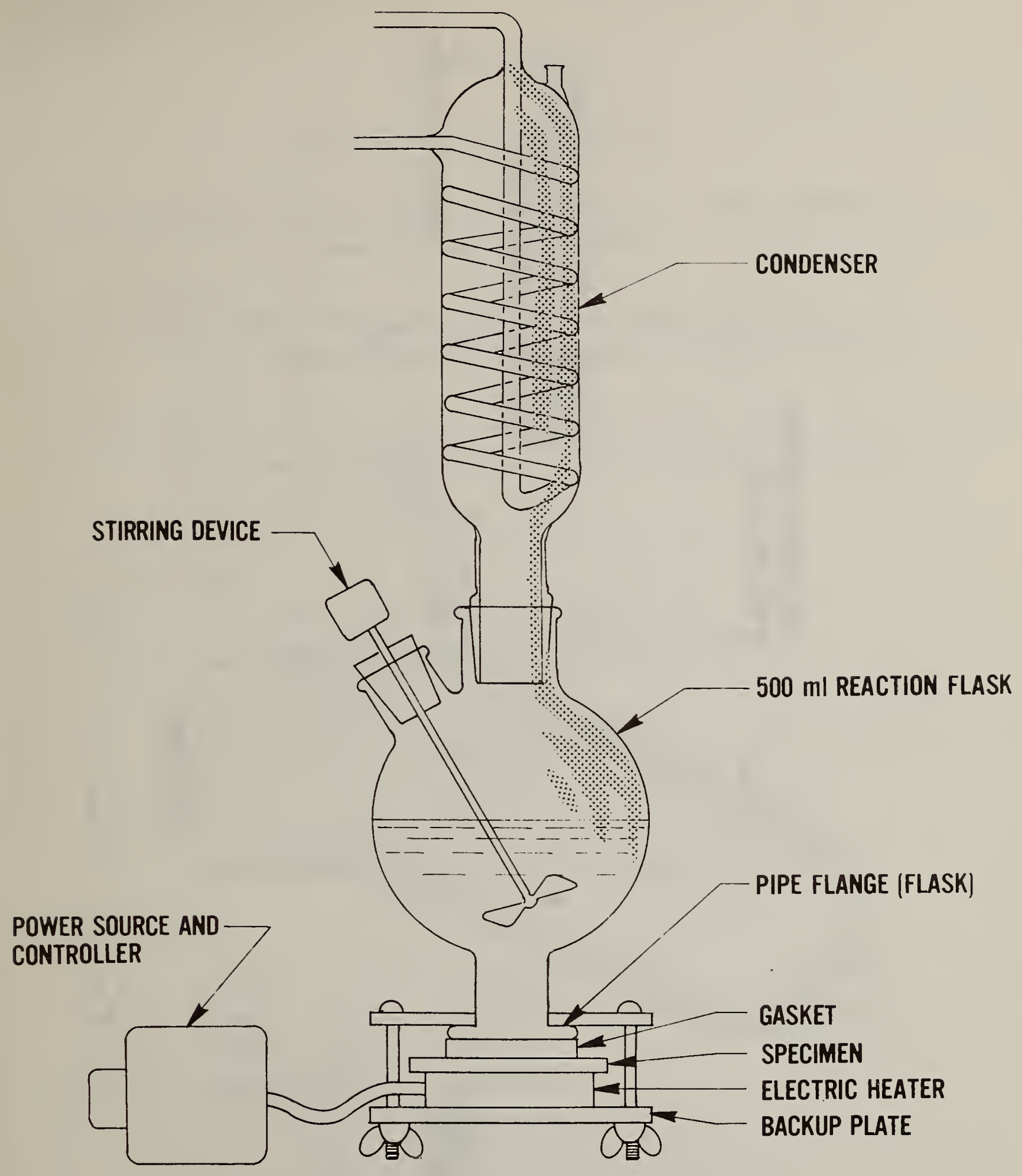

Figure 1. Schematic of Apparatus for Heat hejecting Surface Test. 


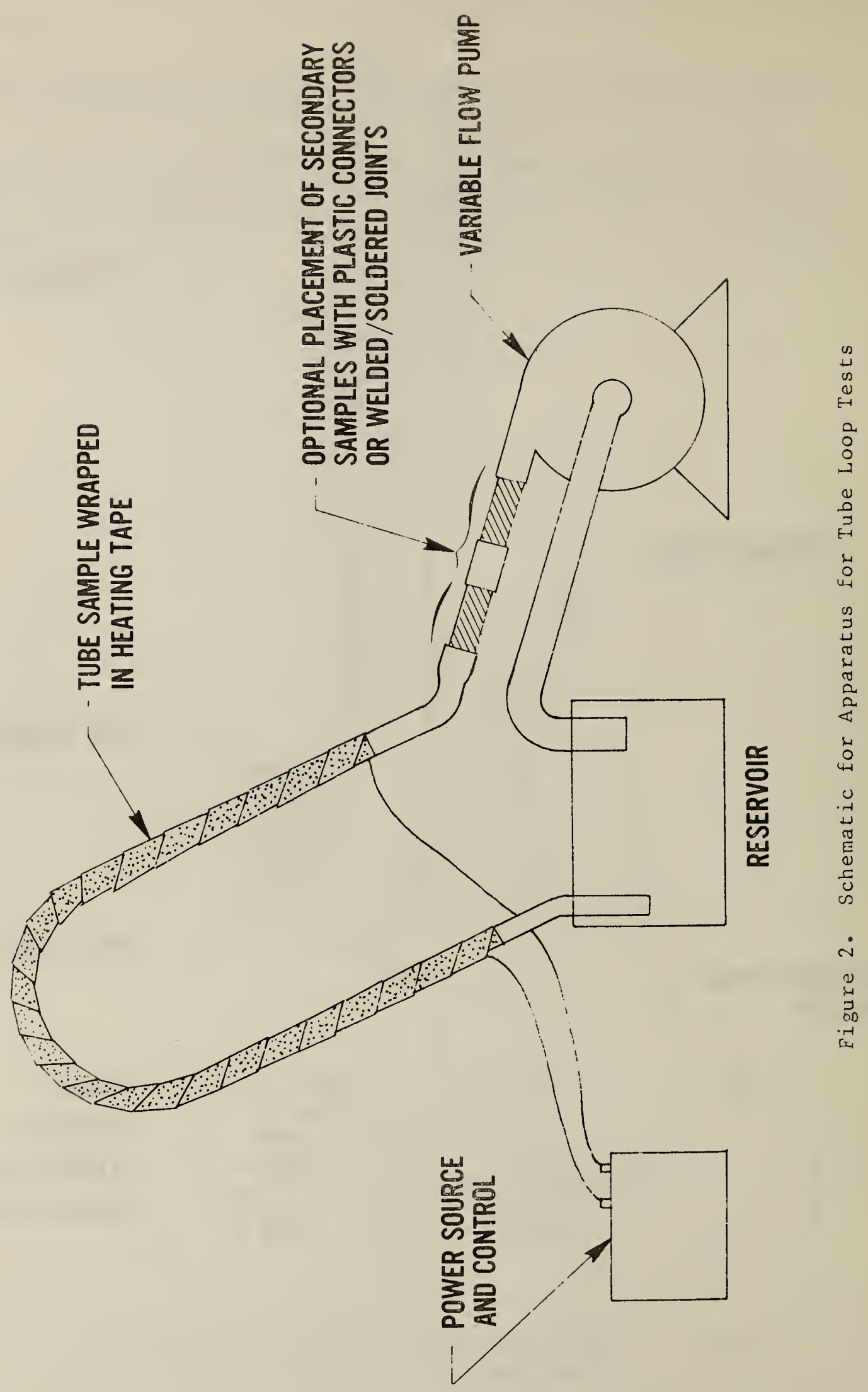




\section{APPENDIX II}

\section{Specimen Cleaning Procedures [1]}

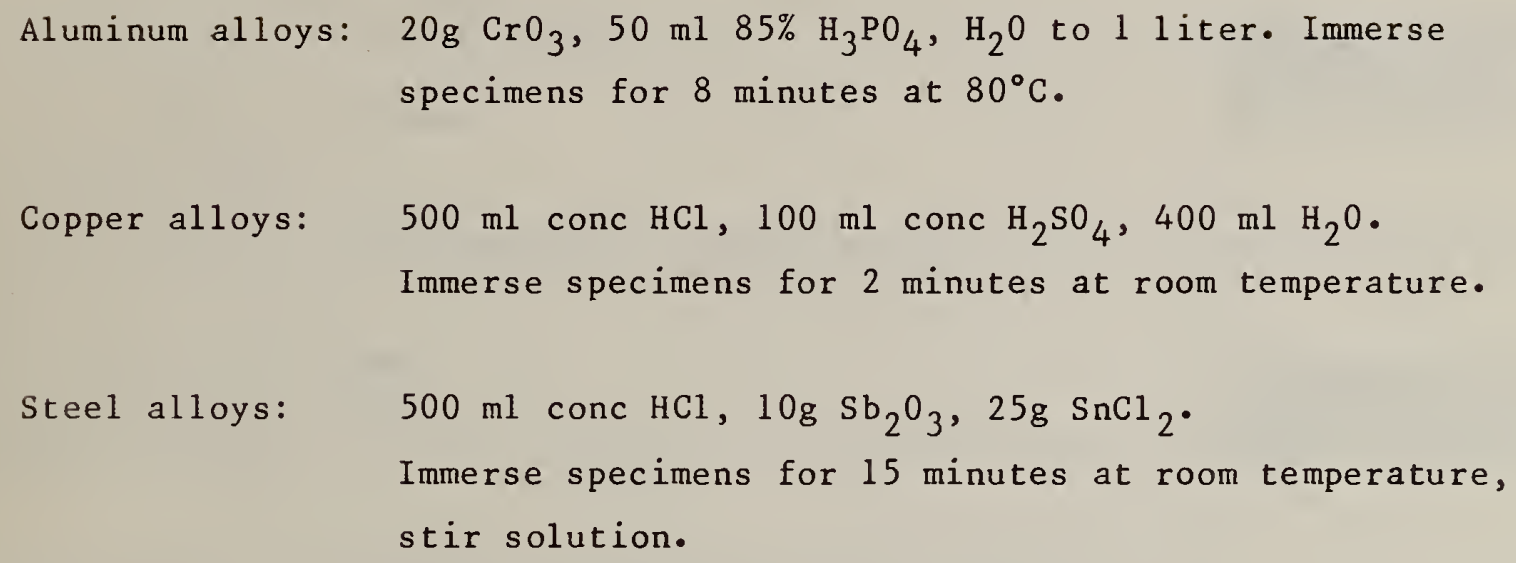

APPENDIX III

Typical blank correction factors for 1 inch by 2 inch ( $25 \mathrm{~mm}$ by $51 \mathrm{~mm}$ ) specimens, grams

$\begin{array}{rllcl}1100 \mathrm{Al} & 0.00023 & 409 \mathrm{~s} / \mathrm{s} & \text { negligible } \\ 3003 \mathrm{Al} & 0.00038 & 439 \mathrm{~s} / \mathrm{s} & \text { negligible } \\ 122 \mathrm{Cu} & 0.00066 & 444 \mathrm{~S} / \mathrm{S} & \text { negligible } \\ 706 \mathrm{Cu} & 0.00059 & 1015 \mathrm{Steel} & 0.00430\end{array}$



NBS.114A IREV. 9-7B)

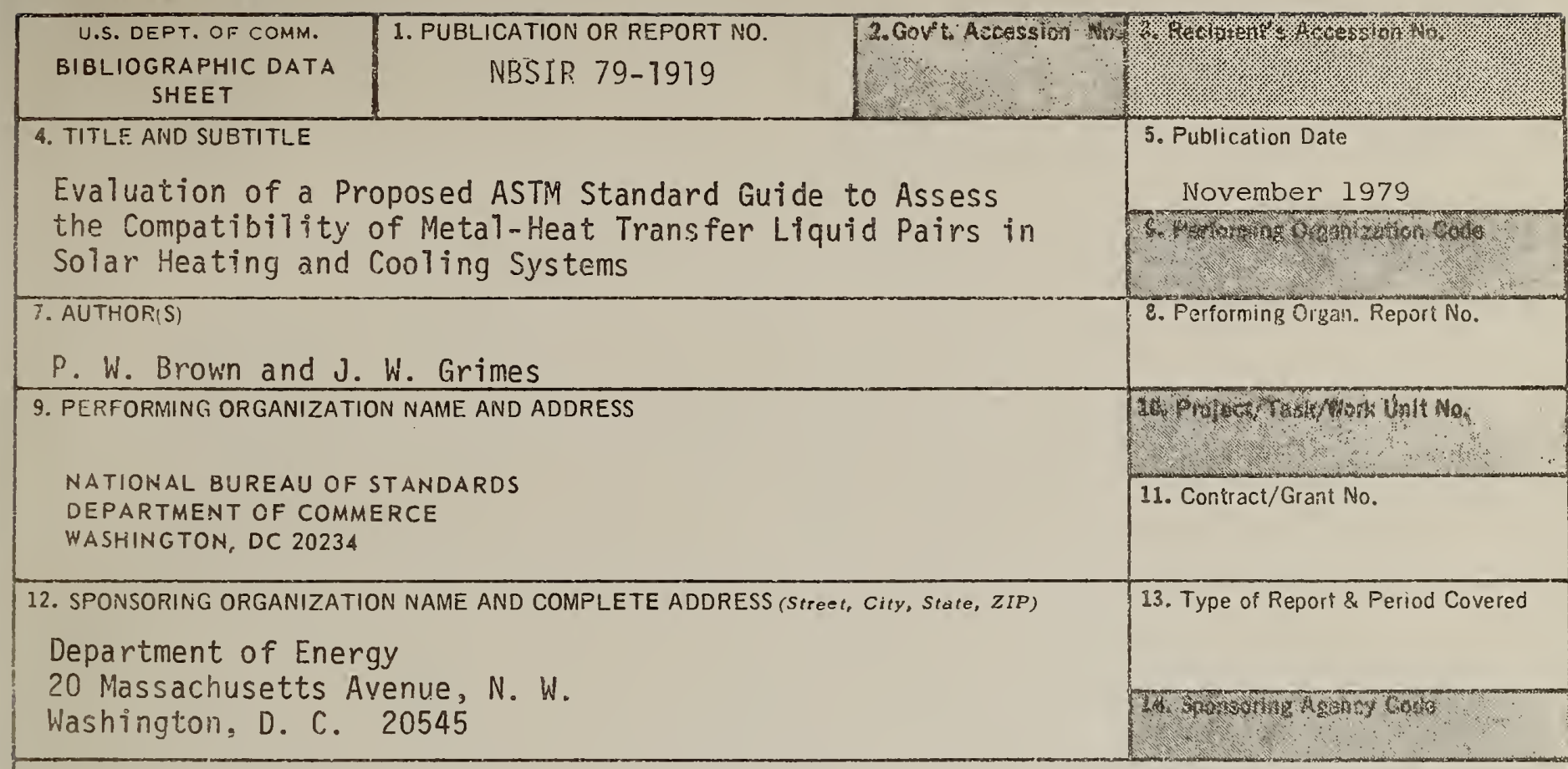

15. SUPPLEMENTARY NOTES

Document describes a computer program; SF..185, FIPS Software Summary, is attached.

16. ABSTRACT (A 200-word or less foctual summary of most significant information. If docunient includes a significent bibliografhy or literature survey, mention it here.)

This study was undertaken as part of a round-robin evaluation of a proposed American Society for Testing and Materials (ASTM) testing methodology entitied, "Standard Guide for Laboratory Screening of Metal7ic Containment Materials for Use with Liquids in Solar Heating and Cooling Systems." This study was undertaken solely to evaluate the procedural aspects of each test method and the results of this study are not intended to provide an assessment of the suitability of any of the metals evaluated for use in solar heating and cooling systems. It was determined that the tests described in this Standard Practice can be carried out as a basis for evaluating metal-heat transfer liquid pair interactions under conditions simulative of various modes of solar containment system operation.

17. KEY WORDS (six to twelve entries; alphabetical order; capitalize only the first lettcr of the first key word unieas a proper namo; separated by semicolons)

Solar-Heat Transfer Liquid Containment; corrosion; elevated temperature; heat transfer; liquid flow rate; stagnation

\begin{tabular}{|c|c|c|}
\hline 18. AVAILABILITY $\quad X$ Unlimited & $\begin{array}{l}\text { 19. SECURITY CLAASS } \\
\text { (THIS REPORT) }\end{array}$ & $\begin{array}{l}\text { 21. NO. OF } \\
\text { PRINTED PAGES }\end{array}$ \\
\hline I For Official Distribution. Do flot Release to NTIS & UNCLASSIFIED & 44 \\
\hline $\begin{array}{l}\text { Order From Sup. of Doc., U.S. Government Printing Office, Wasinington, DC } \\
20402 \text {, SD Stock No. SNO03-003- }\end{array}$ & $\begin{array}{l}\text { 20. SECURITY CLASS } \\
\text { (THIS PAGE) }\end{array}$ & 22. Price \\
\hline $\begin{array}{l}\text { X| Order From National Technical Information Service (NTIS), Springfield, } \\
\text { VA. 22161. }\end{array}$ & UNCLASSIFIED & $\$ 4.50$ \\
\hline
\end{tabular}



